\title{
Prediction of Crude Oil Prices using Hybrid Guided Best-So-Far Honey Bees Algorithm-Neural Networks
}

\author{
Nasser Tairan ${ }^{1}$, Habib Shah $^{2}$, Aliya Aleryani ${ }^{3}$ \\ Department of Computer Science, College of Computer Science \\ King Khalid University Abha, Saudi Arabia
}

\begin{abstract}
The objective of this paper is the use of new hybrid meta-heuristic method called Guided Best-So-Far Honey Bees Inspired Algorithm with Artificial Neural Network (ANN) on the Prediction of Crude Oil Prices of Kingdom of Saudi Arabia (KSA). Very high volatility of crude oil prices is one of the main hurdles for the economic development; therefore, it's the need of the hour to predict crude oil prices, especially for oil-rich countries such as KSA. Hence, in this paper, we are proposing a hybrid algorithm, named: Guided Best-So-Far Artificial Bee Colony (GBABC) algorithm. The proposed algorithm has been trained and tested with ANN for finding the optimal weight values to increase the exploration and exploitation process with balance quantities to obtain the accurate prediction of crude oil prices. The KSA crude oil prices of the five years 2013 to 2017 have been used to train ANN with different topologies and learning parameters of the proposed method for the prediction of the crude oil prices of the next day. The simulation results have been very promising and encouraging of the proposed algorithm when compared and analyzed with ABC, GABC (Gbest Guided ABC) and Best-So-Far ABC methods for prediction purpose. In most cases, the actual prices and predicted crude oil KSA prices are very close, which were obtained by the proposed GBABC method based on the optimal weight values of ANN and minimum prediction error.
\end{abstract}

Keywords—Bio inspired; best so far; crude oil prices; KSA

\section{INTRODUCTION}

Crude oil, commonly known as petroleum comes from an oil well, is a liquid or solid found within the explored earth comprised of hydrocarbons (compounds composed mainly of hydrogen and carbon), organic compounds and small amounts of metal [1]. It is one of the most important energy resources on earth for humans and machine developments. So far, it remains the world's leading fuel, with nearly one-third of global energy consumption.

Among the other natural resources, crude oil is the "key" treasure for obtaining the stable economic position of the country. It has an important factor affecting the local and global economy of the region as well. For the last two decades, the oil-rich countries have witnessed significant margins and differences in their development rate, economic stability as well as the quality of their organizations. KSA is one of the oilrich, productive hub resources in the Middle East region. Its cover more than half of the OPEC's total oil exports, and is a major player in setting the oil price in Asia and worldwide [2]. The country, being the second largest producer of petroleum liquids and the largest exporter of crude, has the ability to have a major impact on the global oil industry and economic stability. KSA has 265.8 billion barrels of crude reserves, the second largest in the world, amounting to $16 \%$ of the world's reserves in 2014, which are predicted to rise to 273 billion by the end of 2017 [3]. KSA is also the second largest producer of crude oil in the world. From May to June 2017, the crude Oil Production in Saudi Arabia increased $9880 \mathrm{BBL} / \mathrm{D} / 1 \mathrm{~K}$ to $10070 \mathrm{BBL} / \mathrm{D} / 1 \mathrm{~K}[4]$.

It has the highest refining capacity among the OPEC producers and has plans to add 1.2 million bbl/d more by 2020 to the current refining capacity of crude oil of 2.9 million bbl/d. In 2016, the top three crude oil producing countries were Saudi Arabia $(10.46 \mathrm{~m} \mathrm{~b} / \mathrm{d})$, Russia $(10.29 \mathrm{~m} \mathrm{~b} / \mathrm{d})$ and the United States $(8.88 \mathrm{~m} \mathrm{~b} / \mathrm{d})[5]$. It's come in twelfth largest primary energy consumer in the world like around 1 million bbl/d of oil is used for electricity generation during the heat waves season [2].

The famous upstream and downstream companies operating in KSA are Saudi Aramco, Shell, Total, Chevron, Sinopec, ExxonMobil, Sumitomo and Eni. The country has around 100 oil fields; the five famous in the production are Safaniya, Khurais, Manifa, Shaybah and Ghawar. The Ghawar oil field has the maximum production and estimated proved oil reserves of 70 billion barrels as of 2014. The production of oil in 2014 was 9.7 million bbl/d, which was $32 \%$ and $10.5 \%$ of the OPEC's and the global crude oil production respectively. International Energy Agency, Energy Information Administration has represented the crude oil production of global [6], OPEC and KSA with the following Fig. 1 [7].

Predicting oil prices brought a considerable attention by scientific researchers and authors to study it from different aspects and different categories who provide a preemptive knowledge in identifying potential candidate forecasting models for crude oil prices. Unfortunately, with inadequate information, uncertain situation, too many variables, the intrinsic complexity of oil market mechanisms, imbalance between production and consumption, weather forecasting, and imprecise elements, the crude oil price system is extremely complex for modeling analyses, and its dynamics are hard to predict its future price [8]. Oil prices are confined between demand and supply framework, oil price volatility analysis and Oil price forecasting [9].

The world crude oil prices from 2004 to 2018 are given in Fig. 2 [10], [11]. Due to the high volatility in the crude oil price, Saudi Arabia has found itself between a rock and a hard place lately. Based on the previous study [9], [10], [11], a relationship between crude oil price, economic activities, 
energy supply and distribution and the gross domestic product (GDP) growth rate are asymmetric [12]. The role of oil price in the prediction of economic growth has been investigated [4], [13] which demonstrated a higher level of predictability of 28 developed countries. The petroleum sector accounts for roughly $87 \%$ of budget revenues, $42 \%$ of GDP, and $90 \%$ of export earnings [14].

The annual GDP of KSA (The recent years) is decreasing due to the high volatile of unreliable crude oil price in the global market as given in Fig. 3. Therefore, the economist exploiting new income resources for stable GDP value through different innovative, nationalization, global business strategies, promoting education and energy sector through mission 2030 scheme. Due to its high complexity and price volatility, researchers adopted various statistical, mathematical, artificial intelligence, hardware base, computer science knowledge and software based and engineering methods for the prediction of accurate price of crude oil of KSA. The Autoregressive integrated moving average (ARIMA) and gene expression programming (GEP) techniques used to predict crude oil prices over the period from January 2, 1986 to June 12, 2012 [16].

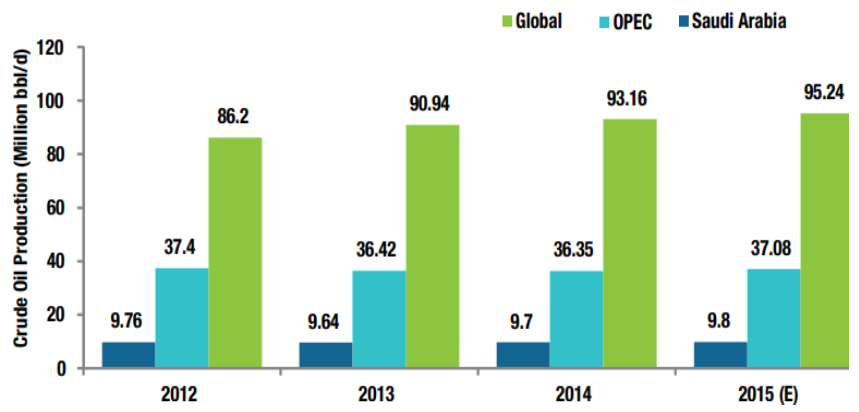

Fig 1. Crude Oil Production of 2018 (average per month).

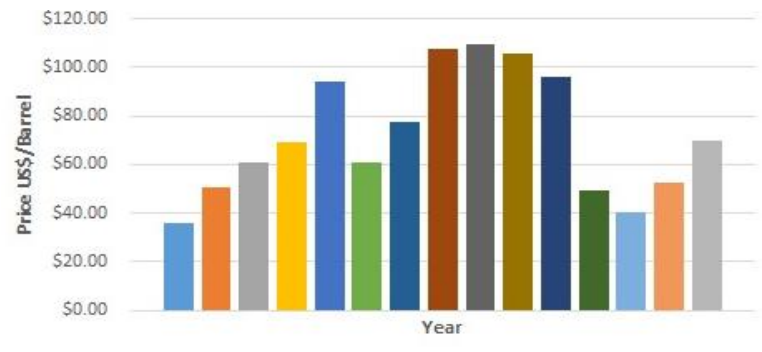

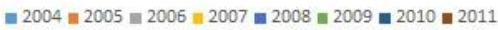

| $2012=2013=2014=2015=2016=2017=2018$

Fig 2. Fifteen Years (2004-2018) Global Crude Oil Prices[15].

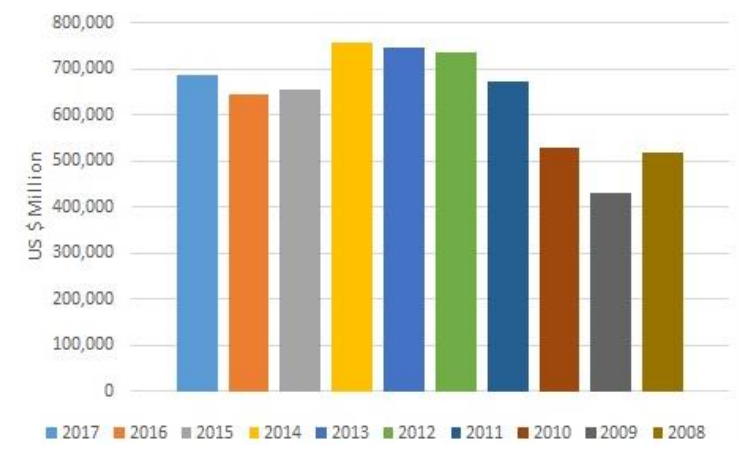

Fig 3. The GDP of KSA from 2008 to 2017 (Million USD).
The GEP model outperforms the ARIMA has the highest explanatory power as measured by the R-squared statistic. However, the GEP didn't successes in obtaining high prediction accuracy. The hybrid model integrating wavelet and multiple linear regressions (WMLR) was proposed for crude oil price forecasting of WTI obtained higher accuracy than regular LR (Learning Rate), ARIMA, and generalized autoregressive conditional heteroscedasticity (GARCH) model [8], however this method used multiple steps such as Particle Swarm Optimization (PSO) for adopting parameters and principal component analysis for processing subseries data. The ARIMA, GARCH, Belief networks, k-means clustering and an empirical mode decomposition (EMD) methods have used for crude oil forecasting in the last two decades [9], [17]. However, due to the volatility, nonlinearity, and irregularity, the classical and econometric model can lead to the decrease of the accuracy. Therefore, due to the above mentioned limitations of the classical science, mathematical and statistical approaches, soft-computing models can provide powerful solutions to nonlinear crude oil price prediction [18].

Many experiments found that the computational intelligent algorithms which simulate the way humans' reason by incorporating their rate of efficiency and randomness during decision making. They have broadly divided into techniques based on modelling of human mind and nature inspired algorithms [19], [20]. These methods often have some advantages over typical mathematical and statistical-based models [21]. However, these models also have their own drawbacks, such as ANN often suffer from local minima and over-fitting problems, while SVM and GP, including ANN, are sensitive to parameter selection and suitable architectures and dataset behaviors [22], [23]. Also, the standard learning algorithms of the ANN models have the same local minima trapping problem and slow convergence speed [24], [25].

To remedy the above shortcomings of typical models and learning algorithms, meta-heuristic and their hybrid version methods have been used recently to solve time series problems. These are: Artificial Bee Colony (ABC), Cuckoo Search (CS), Bat Algorithm (BA), evolutionary algorithms (EA), genetic algorithm (GA), PSO, Ant Colony Optimization, hybrid algorithms and so on [26]-[30]. These meta-heuristic learning algorithms are more efficient and famous due fast convergence, high efficiency, easy to understand and implementation and robustness for some problems [31], [32]. They can easily find the set of best weight values, through suitable parameter selection, activation function and network structure that will cause the output from the MLP to match the actual target values as closely as possible.

Sections 2 and 3 contain neural networks and crude oil prices forecasting details and honey bees super heuristic optimization methods respectively. The proposed method explained in Section 4. The simulation results and conclusion are added in Sections 5 and 6.

\section{NeURAL NETWORKS AND OIL PRICES ForECASTING}

Artificial neural network (ANN) often called a "Neural Network" or simply Neural Net (NN) inspired by biological system is an interconnected set of artificial neurons that uses a mathematical model or computational model for information 
processing based on external or internal information that flows through the network [33]. The biological neuron structure is given in Fig. 4, which have different functions terminologies such as dendrites, which receive activation from other neurons, some processes which converts incoming activations into output activations, axons act as communication route, synapses, neurotransmitters and nucleus. This field goes by many names, such as parallel distributed processing, Neurocomputing, natural intelligence systems, machine learning algorithms, bio inspired learning methods, deep learning and Multilayer Perceptron (MLP), and others soft computing methods [33], [34], [35].

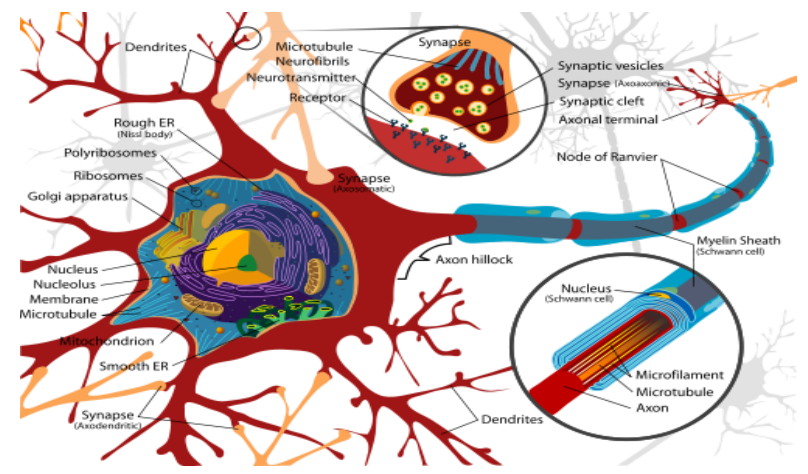

Fig 4. Structure of biological neuron.

TABLE I. Previous Research ON CRUde OIL Prices Prediction

\begin{tabular}{|c|c|c|c|}
\hline ANN Model & Input Patterns & Objectives & Findings \\
\hline $\begin{array}{l}\text { Feedforward with Levenberg- } \\
\text { Marquardt algorithm [44] }\end{array}$ & Daily closing price from Sep 2002 to Aug 2013. & short-term prediction & better than the LSM \\
\hline $\begin{array}{l}\text { feed-forward neural network and } \\
\text { Radial Basis Function[16] }\end{array}$ & January 2, 1986 to June 12, 2012. & forecast oil price & $\begin{array}{l}\text { Less mean squared error than gene } \\
\text { expression programming }\end{array}$ \\
\hline $\begin{array}{l}\text { Artificial Neural Networks- } \\
\text { Quantitative with BP [45] }\end{array}$ & $\begin{array}{l}\text { Crude oil dataset of } \\
1984 \text { to February, } 2009 \text { with quantitative key } \\
\text { factors influencing. }\end{array}$ & $\begin{array}{l}\text { monthly WTI crude oil } \\
\text { price prediction }\end{array}$ & $\begin{array}{l}\text { ANN-Q model effective than } \\
\text { Hierarchical Conceptual model }\end{array}$ \\
\hline $\begin{array}{l}\text { Empirical Mode Decomposition } \\
\text { with Feed-forward Neural Network } \\
\text { and Adaptive Linear Neural } \\
\text { Network [46]. }\end{array}$ & $\begin{array}{l}\text { The data frequency is } \\
\text { daily closing price; from Sep } 1996 \text { to Aug } 2007 \\
\text { of WTI }\end{array}$ & $\begin{array}{l}\text { short-term prediction up to } \\
\text { three days ahead }\end{array}$ & $\begin{array}{l}\text { Intraday data for crude oil prices is not } \\
\text { available, overall improvement was } \\
\text { insignificant }\end{array}$ \\
\hline $\begin{array}{l}\text { Functional Link Artificial Neural } \\
\text { Network And MLP [47] }\end{array}$ & $\begin{array}{l}\text { US dollar index, } \\
\text { S\&P } 500 \text { stock price index, gold spot price, } \\
\text { heating oil spot price and US crude oil spot } \\
\text { price are employed }\end{array}$ & $\begin{array}{l}\text { predict the next day's spot } \\
\text { price of US crude oil }\end{array}$ & $\begin{array}{l}\text { Functional link artificial neural network } \\
\text { performed better than standard MLP. }\end{array}$ \\
\hline $\begin{array}{l}\text { Stream learning, Random guess } \\
\text { and Forecast combination models } \\
{[48]}\end{array}$ & $\begin{array}{l}\text { U.S. refiner } \\
\text { acquisition cost for crude oil imports and WTI } \\
\text { crude oil spot price, }\end{array}$ & $\begin{array}{l}\text { Predict monthly crude oi } \\
\text { price }\end{array}$ & $\begin{array}{l}\text { Highest accuracy than no-change and } \\
\text { ANN, Random guess and Forecast } \\
\text { combination models. }\end{array}$ \\
\hline $\begin{array}{l}\text { factor augmented artificial neural } \\
\text { network(FAANN) [40] }\end{array}$ & $\begin{array}{l}\text { South African monthly panel, namely, deposit } \\
\text { rate, gold mining share prices and Long-term } \\
\text { interest rate, using monthly data over the in- } \\
\text { sample period (training set) 1992:1-2006:12. }\end{array}$ & $\begin{array}{l}\text { to forecast } 3,6 \text { and } 12 \\
\text { month-ahead forecasts }\end{array}$ & $\begin{array}{l}\text { FAANN model yields substantial } \\
\text { improvements over the autoregressive } \\
\text { AR benchmark model and standard } \\
\text { dynamic factor model (DFM). }\end{array}$ \\
\hline $\begin{array}{l}\text { Time-varying weight combination } \\
\text { approach [49] }\end{array}$ & $\begin{array}{l}\text { factors: supply, demand, crack spread, and non- } \\
\text { energy commodity prices. West Texas } \\
\text { Intermediate crude oil prices Dataset }\end{array}$ & $\begin{array}{l}\text { mid-horizons and long- } \\
\text { horizons }\end{array}$ & Limited horizons \\
\hline $\begin{array}{l}\text { deep learning ensemble } \\
\text { approach[50] }\end{array}$ & $\begin{array}{l}\text { West Texas Intermediate } \\
\text { price series, flow and } \\
\text { stock series, and macroeconomic and } \\
\text { financial series }\end{array}$ & $\begin{array}{l}\text { Monthly WTI crude oil } \\
\text { price }\end{array}$ & Effective with largest computational cost \\
\hline Deep Learning based Model [51] & $\begin{array}{l}\text { historical data of the WTI crude oil market, } \\
\text { July 23, } 2007 \text { to February 24, } 2017\end{array}$ & $\begin{array}{l}\text { Daily crude oil price } \\
\text { movement prediction }\end{array}$ & Limited deep learning models \\
\hline convolutional neural network[52] & $\begin{array}{l}\text { Brent crude oil generic series of the first } \\
\text { month's futures prices, traded on the } \\
\text { Intercontinental Exchange (ICE) from } 24 \text { June } \\
\text { 1988, to } 3 \text { November } 2018 \text {. }\end{array}$ & $\begin{array}{l}\text { short-term crude oil } \\
\text { futures prices prediction }\end{array}$ & $\begin{array}{l}\text { Only working for short-term crude oil } \\
\text { futures prices. }\end{array}$ \\
\hline
\end{tabular}




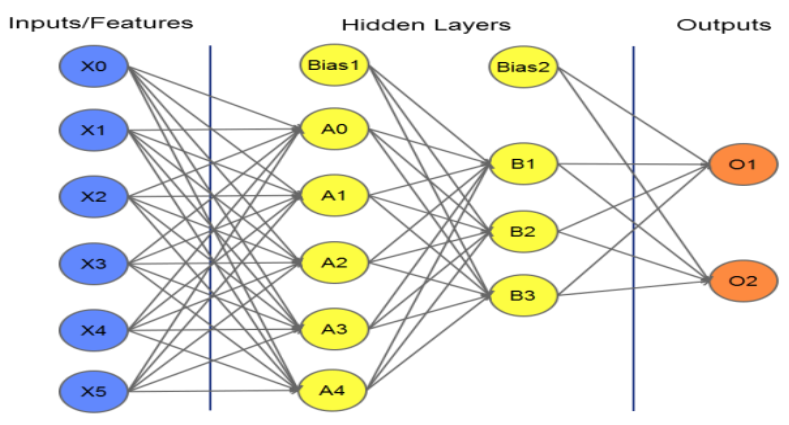

Fig 5. Artificial neural network.

Based on the biological neuron of Fig. 4, McCulloch-Pitts introduced a simplified model called artificial neuron model as given in Fig. 5. The output formula of the artificial neuron model is given in Equation (1).

$$
\text { Output }=\operatorname{sgn}\left(\sum_{i=1}^{n} \operatorname{Input~} i-\Phi\right)
$$

Initially, it was developed for solving linear problems; later on it has been extended to different models such as Multilayer Feedforward Neural Network (MFFN), Recurrent Neural Network, Probabilistic Neural Network, Pi Sigma Neural Network for solving different optimization problems [33], [34]. MFFN is a famous among the various NN structure most commonly used due to its lower complexity and ability to produce satisfactory results for different problem domains as given in Fig. 6.

The previous study shows that the NN performance can be improved through the selection of suitable structure, activation function, appropriate numbers of input pattern and of course learning algorithms. Besides the common applications, ANN tools are very effective for financial, stationary and nonstationary, meteorological, natural hazards, stock values and crude oil price time series data prediction. For two decades, ANN tools are famous, effective and attractive for prediction time series dataset including crude oil prices, bottom hole pressure in vertical multiphase and stock exchange values [36].

Using MFFN model reached on minimum error and high accuracy through different learning strategies such as supervised, unsupervised and reinforced, such as, backpropagation, genetic algorithm, gradient descent and so on. Typical training algorithm, BP has some drawbacks like slow convergence and trapping in local minima [37], [38]. The Bayesian approach used to predict crude oil price through the various independent variable factors such as world oil demand and supply, the financial situation, upstream costs, and geopolitical events. The results show that the crude oil price is estimated to increase to $\$ 169.3 / \mathrm{Bbl}$ by 2040 [39].

However, these models used the traditional machine learning algorithms, rely on a fixed set of training data to train a machine learning model and then apply the model to a test set, but may not be effective for non-stationary time series data such as oil price data and other nonlinear complex dataset. From the above-mentioned approaches, that ANN model is more sufficient and effective than standard models; the performance can be easily increased rapidly through robust and efficient learning algorithm [23], [40], [41]. Bio-Inspired methods are robust and attractive optimization algorithm especially for solving nonlinear complex problems [42], [43]. The previous histories of softcomputing methods for crude oil prices prediction are summarized in Table I.

\section{Honey BEES META-HeURISTIC OPTIMIZATION METHODS}

\section{A. Bio-Inspired Artificial Bee Colony}

The Artificial Bee Colony ( $\mathrm{ABC}$ ) is a robust bio-inspired learning method, proposed in 2005 by Karaboga [53] to solve the complex nonlinear optimization problem in multivariable functions, is a relatively innovative meta-heuristic optimization algorithm that is based on the social behavior of honey bee colony named: employed bees, onlooker bees and scouts during searching and managing for food sources (FS) [54]. The first half of the colony consists of the employed bees and the second includes the unemployed. From the different numerical and statistical performance measure demonstrate that the $\mathrm{ABC}$ algorithm is competitive with other types of meta-heuristic and typical algorithms [55]-[57]. The technical duties of the employed and unemployed artificial bees are given in details.

Each employed bee search around the food source, gathering required information about its quality and position of the onlookers. Then, they carry the information about the position of food source back to the hive and share this information with artificial onlooker bees by dancing in the nearby hive. Onlooker bees: the onlookers tend to choose the best food sources to further exploit, based on information communicated by the employed bees through their dances. Therefore, good food sources attract more onlooker bees compared to the bad ones. The artificial onlooker bees choose the best food source with better quality based on information communicated from those found by employing bees using different ways, such as a probability selection mechanism, greedy selection, fitness function as a proportional of the quality of the food source. The last bees processes are managing by the scout bee group is responsible for the exploration process randomly chose a new good food source to replace the old one. The number of food sources (based on position and quality) which represents a possible solution to the optimization problem and fitness of the associated solution is equal to the number of employed bees and also equal to the number of onlooker bees. The employed, onlooker bees used for exploitation process for a given problem towards best solution space given in Equation (2), while scout bees Equation (3) for exploitation process.

$$
v_{i j}=x_{i j}+\Phi_{i j}\left(x_{i j}-x_{k j}\right)
$$

Where $v_{i j}$ is a new solution in the neighborhood of $x_{i j}$ for the employed bees, $k$ is a solution in the neighborhood of $i, \Phi$ is a random number in the range $[-1,1]$.

$x_{i j}^{\text {rand }}=x_{i j}^{\min }+\operatorname{rand}(0,1)\left(x_{i j}^{\max }-x_{i j}^{\min }\right)$

Although typical $\mathrm{ABC}$ is famous due to its robustness and high efficiency for clustering, classification and numerical function optimization problems, however, due to the same and 
the random searching approach of exploration cannot guaranty for finding the best food position, also sometimes it trapped in local minima. The researchers improved typical $A B C$ algorithm by different strategies such as, Best-So-Far, discrete, hybrid, gbest guided and quick within employed, onlookers and scout bees. The typical artificial bee colony model which includes three kinds of bees considering the division of labor: employed bees, onlooker bees and scout bees. Each employed bee works on only one food source as given in Fig. 6.

\section{B. Best-So-Far Artificial Bee Colony Algorithm}

The standard ABC algorithm is a unique bio inspired algorithm inspired through the attraction and natural foraging behaviors of honey bees. It has been successfully used for solving different statistical, mathematical, science and engineering problems. The exploration and exploitation are the famous process of $\mathrm{ABC}$ by employed and unemployed bees [58]-[62].

Equations (2) and (3) were used for exploitation through employed and onlooker bees and scout bee for exploration process. The first two bee group used the same exploitation process base on random way which cannot guarantee for optimized and fast solution. Therefore, the Best-So-Far ABC proposed [63], is one of the efficient bio inspired algorithm among the $\mathrm{ABC}$ improved and hybrid algorithms. It was developed to enhance the exploitation and exploration processes of typical ABC through different strategies: the BestSo-Far method, an adjustable search radius, and an objectivevalue-based comparison method. Equation (2) of the typical $\mathrm{ABC}$ has been reused in the exploration process. The Best-SoFar $\mathrm{ABC}$ updated the exploitation process of onlooker bees section by the following Equation (4) as:

$$
\mathrm{v}_{i d}=x_{i j}+\Phi_{\mathrm{ij}} f_{b}\left(x_{i j}-x_{b j}\right)
$$

where: $v_{i d}$ is the new candidate food source for onlooker bee position $i$ dimension $d, \mathrm{~d}=1,2, \ldots, \mathrm{D} ; \mathrm{x}_{\mathrm{ij}}$ is the selected food source position $\mathrm{i}$ in a selected dimension $\mathrm{j} ; \Phi=\mathrm{a}$ random number between -1 and $1 ; f_{b}$ is the fitness value of the best food source so far and $x_{b j}$ is the Best-So-Far food source in selected dimension $j$.

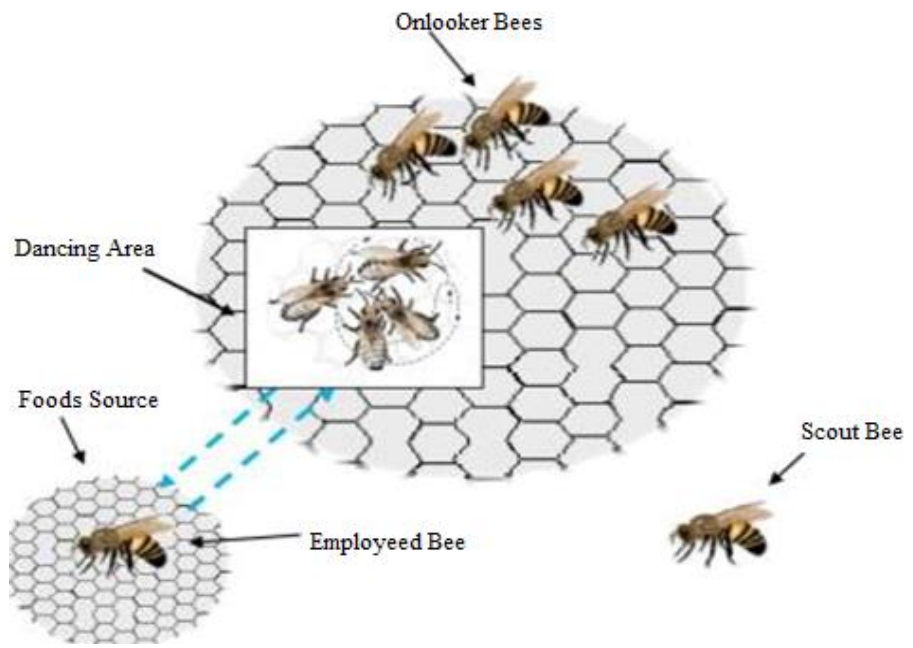

Fig 6. A Typical Bee Colony Model The artificial bee colony includes three kinds of bees considering the division of labor: employed bees, onlooker bees and scout bees. Each employed bee works on only one food source.
The best food source position is calculated by processing the information received from all employed bees. The onlooker bees using Best-So-Far method will record the best selected food source position so far within the new candidate generation function to enhance the exploitation process. Then the fitness method used to calculate fitness based on that particular best solution, which used to compare with other previous fitness values, the position is updated with Equation (4) based on the fitness level. The second modification made in the adjustable search radius. This is done because of the need to get out of the local optimum solution problem.

$$
v_{i d}=x_{\mathrm{ij}}+\Phi_{i j}\left[w_{\max }-\left(\frac{\text { iteration }}{M C N}\right)\left(w_{\max }-w_{\min }\right)\right] x_{i j}
$$

Where $v_{i d}$ is a new achievable solution of a scout bee that is modified from the present position of an abandoned food source $\left(x_{i j}\right)$, the value of $w_{\max }$ and $w_{\min }$ represent the maximum and minimum percentage of the position adjustment for the scout bee. The last change is finding the minimum objective value, here compare and to select between the old solution and the new solution in each iteration is done by the fitness value of the following Equation (6) as,

$$
\text { Fitness }(\mathrm{f}(\mathrm{x}))= \begin{cases}\frac{1}{1+f(x)} & \text { if } f(x) \geq 0 \\ 1+|f(x)| & \text { if } \quad f(x)<0\end{cases}
$$

The above proposed method is efficient and fast convergence through three modifications for solution update, increase the local search ability of the onlooker bees, maintain the diversity of new food sources by random scout bees, and to resolve round up issues in the computation of the floating point "goodness" value. However, the employed bees section used the random way Equation (2) of typical ABC, which can lead to unbalance of exploration and exploitation process for different complex problems.

\section{Gbest Guide Artificial Bee Colony Algorithm}

The typical $\mathrm{ABC}$ algorithm used the random searching and selecting methods through employed, onlooker and scout bees, unfortunately no global best solution, best-so-far, local, best or mutation method use to improve and balance the exploration and exploitation process successfully. Based on random searching ways, ABC has global search capability, but poor local search capability. In order to enhance the exploitation capability of the ABC algorithm through candidate solutions like employed bee. Different improved version of typical ABC have been developed for enhancing and balance exploration and exploitation process by introducing different operators, strategies and operators. Gbest Guided Artificial Bee Colony (GABC) algorithm is one of the attractive modified bio inspired algorithm developed to increase the performance of typical ABC [59]. Equation (2) has been modified by the Equation (7) to direct the search path towards global optima.

$$
v_{i j}=x_{i j}+\Phi_{i j}\left(x_{i j}-x_{k j}\right)+\Psi_{i j}\left(y_{j}-x_{i j}\right)
$$

where $v_{i j}\left(\right.$ or $x_{i j}$ ) is a new solution in the neighborhood of $x_{i j}$ for the guided employed bees and onlooker bee, $\Psi \mathrm{ij}$ is a random number in the interval between $[0, \mathrm{C}]$, and the term $y_{j}$ 
represents jth element of the global best solution in current generation. The equation (7) used to enhance the exploitation process through gbest $x_{j}$ and $\mathrm{c}$ values. The proposed gbest guided approach is more effective than typical ABC especially for numerical function optimization, time series prediction and for environmental/ economic dispatch considering wind power and classification task [64], [65].

\section{Proposed GBEST GuIDED BEST-SO-FAR ABC ALGORITHM}

Bio inspired agents have motivated many researchers to develop various mathematical and computational approaches for solving complex optimization problems [28], [43], [66], [67]. Theoretically, it is because of their unique movements of searching, gathering, sharing, dancing, foraging, selection, flying, managing, building, communication, social, emotional, their foraging behavior, their mating and reproduction behavior, their pheromone laying behavior and navigation behavior, self-adapting and self-organizing characteristics [68], [69].

These bio inspired artificial agents or methods have successfully applied to various applications and linear, nonlinear complex problems such as classification, clustering, time series prediction, numerical function optimization and other combinatorial problems [70]. The performance of these algorithms depends on exploration, exploitation, balancing, convergence and global optimum position. The typical ABC easily trapped in local minima which lead to slow convergence. Beside ABC, the GABC and Best-So-Far ABC is the modern improved examples in success history as mentioned in the above sections [58], [60].

Taking the advantages of high exploration and exploitation process from GABC and Best-So-Far algorithm, a new hybrid method is proposed called a Guided Best ABC algorithm. The proposed GBABC algorithm will increase the effectiveness of typical $\mathrm{ABC}, \mathrm{GABC}$ and Best-So-Far $\mathrm{ABC}$ algorithm [46], [62], [71], [72]. The GBABC will first use the gbest strategy through employing bee to increase the exploitation process according to the given problem, while the onlookers and scout bees will adapt the Best-So-Far method for exploration process with balance quantity.

The searching strategy of employed bees given by Equation (7) will increase the exploitation around the, current best ever food source through the guided strategy to enhance the real foods source position. These food source positions will be shared with the best so far onlooker and scout bees which will further select the most appropriate position for the given problem. In order to accelerate the convergence speed of the GBABC algorithm, the idea of focusing the search around the current best ever food source gbest, best so far, the best fitness formula was proposed. These bees will repeat their intelligence procedures until a predetermined maximum number of cycles (MCN) or the best food source achieved so far. Of course, the enough and balance exploitation and exploration process will successfully escape local optima trapping and slow convergence difficulties. The proposed GBABC method has been used to train the feed-forward neural networks for the crude oil prediction purpose; the details are added in the following section. Beside the proposed GBABC approach, the main difference in the implementation phase which is executing based on max cycle numbers instead of max fitness number of evaluations, which are used by the typical $A B C$, GGABC, Best-so-far ABC and so many others algorithms.

\section{The pseudo-code of GBABC algorithm}

Start

\section{// Initialization}

Initialize the control variables and food source positions; Evaluate the nectar amount of food sources; /* by using the following equation*/

$$
\text { fitness }_{i}=\left\{\begin{array}{l}
\frac{1}{1+f_{i}}, \text { if } f_{i} \geq 0 \\
1+\left|f_{i}\right|, \text { if } f_{i}<0
\end{array}\right.
$$

Cycle $=1$

Repeat $* /($ the termination conditions are not met) /* (Max Cycle Numbers=as mentioned in Table)

/*Gbest Guided Employed Bees' Phase*/

FOR (each gbest guided employed bee)

Produce a new food source following the Eq. (7);

Evaluate the fitness of the new food source;

Calculate the fitness of the explored food source best so far employed bees.

$$
f i t_{i}=\frac{f i t_{i}}{\sum_{i=1}^{S N} f i t_{i}}
$$

Calculate the fitness values and normalize Pi values into [0,1] using Eq. (8)

Memorize the best solution of Gbest Guided Employed Bee So far;

\section{END FOR}

Calculate the probability $\mathrm{P}$ for each food source following the Eq. (10);

$$
p_{i}=\frac{\text { fitness }_{i}}{\sum_{j=1}^{S N} \text { fitness }_{j}}
$$

/* Best-So-Far Onlooker Bees' Phase*/

FOR (each Best-So-Far onlooker bee)

Send Best-So-Far onlooker to food sources depending on P;

Produce a new food source following the Eq. (4);

Evaluate the fitness of the new food source;

Apply greedy selection on the new FS and the old one;

Memorize the best solution of Best-So-Far Onlooker So far;

\section{END FOR}

\section{/* Best-So-Far Scout Bees' Phase*/}

IF (an gbest guided employed bee becomes into a Best-So-Far scout bee)

Send the Best-So-Far scout bee to a new randomly produced food source;

\section{END IF}

Determine the abandoned solution (source), if exists, replace it with a new randomly produced solution $\mathrm{x}_{\mathrm{i}}$ for the Best-So-Far scout bee using the equation (5), 
Memorize the best solution achieved so far

Cycle $=$ Cycle +1

Until Cycle $=\mathrm{MCN}$

End

\section{EXPERIMENTAL EVALUATION AND ANALYSIS}

In this research paper, crude oil prices time series data set of KSA used for one step ahead prediction of the year 2013, 2014, 2015, 2016 and 2017 respectively, which are used in the original form for prediction tasks [73]. The oil prices on Monday, Tuesday, Wednesday and Thursday were used to predict the next week values. Here, the crude oil settlement prices parameter used for predicting the next value versus days. The details of the above dataset have been given in Table II [73]. The various ANN topologies and algorithms parameters were set according to Table III. The main objectives of the $\mathrm{ABC}, \mathrm{GABC}, \mathrm{BABC}$ and GBABC algorithms are to train an FFNN for the prediction of crude oil price through optimal weights, bias, and hidden layer neurons. FFFNN trained with varied number of hidden layer neurons so that the best number of neurons could be obtained through the exploitation and exploration process of the Best-So-Far ABC, GBAC and GBABC algorithms. Different methods used for simulation analysis, which are Mean Square Error (MSE), Normalized Mean Square Error (NMSE), Mean Absolute Percentage Error (MAPE), Root Mean Square (RMSE), accuracy and success rate based on runtimes number Equations (12, 13 and 14). The FFNN trained with $75 \%$ and $25 \%$ of the whole data set with sigmoid function.

TABLE II. CRUdE OIL PRICES DATASET Before PREPROCESSING

\begin{tabular}{|l|l|l|}
\hline Dataset durations & Total days & Dataset \\
\hline 19-08-2013 to 31-12-2013 & 97 & 94 \\
\hline $01-01-2014$ to 31-12-2014 & 261 & 252 \\
\hline $01-01-2015$ to 31-12-2015 & 261 & 252 \\
\hline $01-01-2016$ to 31-12-2016 & 262 & 253 \\
\hline $03-01-2017$ to 01-08-2017 & 155 & 149 \\
\hline Total=19-08-2013 to 01-08-2017 & 1036 & 1000 \\
\hline
\end{tabular}

$$
\begin{aligned}
& M S E=\frac{1}{N} \sum_{i=1}^{n}\left(d_{i}-y_{i}\right)^{2} \\
& N M S E=\frac{\sum_{i=1}^{n}\left(d_{i}-y_{i}\right)^{2}}{\sum_{i=1}^{n}\left(d_{i}-\bar{d}_{i}\right)^{2}} \\
& \text { Accuraccy }=\left(\frac{1}{n} \sum \frac{\left|d_{i}-y_{i}\right|}{\left|d_{i}\right|}\right) * 100
\end{aligned}
$$

$\operatorname{MAPE}=\frac{1}{\mathrm{n}} \sum_{\mathrm{t}=1}^{n}\left|\frac{\mathrm{y}_{\mathrm{t}}-\hat{\mathrm{y}} \mathrm{t}}{\mathrm{y}_{\mathrm{t}}}\right|$

$\operatorname{RMSE}=\sqrt{\frac{1}{\mathrm{n}} \sum_{\mathrm{t}=1}^{n}\left(\mathrm{y}_{\mathrm{t}}-\hat{\mathrm{y}} \mathrm{t}\right)^{2}}$
TABLE III. SETTING OF ANN TOPOLOGIES AND ALGORITHM PARAMETERS

\begin{tabular}{|l|l|l|l|l|}
\hline Algorithm & $\begin{array}{l}\text { No of } \\
\text { Inputs }\end{array}$ & $\begin{array}{l}\text { Hidden } \\
\text { Nodes }\end{array}$ & $\begin{array}{l}\text { Food } \\
\text { Sources }\end{array}$ & Limit \\
\hline ABC & 4 & $2-10$ & $10-20$ & $\begin{array}{l}5,10,15,2 \\
0\end{array}$ \\
\hline GABC & 4 & $2-10$ & $10-20$ & $\begin{array}{l}5,10,15,2 \\
0\end{array}$ \\
\hline $\begin{array}{l}\text { Best-So- } \\
\text { Far }\end{array}$ & 4 & $2-10$ & $10-20$ & $\begin{array}{l}5,10,15,2 \\
0\end{array}$ \\
\hline GBABC & 4 & $2-10$ & $10-20$ & $\begin{array}{l}5,10,15,2 \\
0\end{array}$ \\
\hline
\end{tabular}

The performance of the $\mathrm{ABC}$ and their various updated algorithms depends on the control parameters: such as Colony Size (which can affect the processing speed and optimality values), limit. Through the proper selection of these parameters' values, the exploration and exploitation can be achieved in a balance way with global optima as well.

The simulation results of GBABC compared with $\mathrm{ABC}$, GBAC and Best so far ABC algorithms. The average MSE training and testing, NMSE, accuracy and success rate are given from Table IV to Table VIII, respectively. In terms of MSE training, the ABC, GABC and Best-So-Far reached to $0.000371,7.12 \mathrm{E}-05,3.93 \mathrm{E}-06$ respectively, while the proposed GBABC algorithm success to obtain the most minimum value than typical algorithms with error $3.13 \mathrm{E}-11$ as given in Table IV. In case of 4-8-1, the Best-So-Far method reached to $1.10 \mathrm{E}-08$ which is the minimum error than obtained by $\mathrm{ABC}$, GABC methods.

From the NMSE results as given in Table V, Best-So-Far outperformed than $\mathrm{ABC}$ and $\mathrm{GABC}$ and proposed GBABC algorithm outperformed than all typical algorithms except Best-So-Far with 4-7-1 NN topology. The proposed GBABC obtained the best MSE out of sample data set for crude oil prices prediction than others bio inspired methods as shown in Table VI. Here, again the Best-So-Far method successes in obtaining least testing error when the hidden nodes reached to seven. Based on overall result, the GBABC model is reliable and promising for the accurate prediction of crude oil prices.

The average accuracy and success rate of the proposed and typical methods are given in Table VII and Table VIII. Where the success rate implies the percentage of getting success each time when the program is run with different control parameters. The GBABC prediction accuracy reached at 97.98, 98.70, 99.15, 99.10, 99.87 and with $100 \%$ success rate are higher than $\mathrm{ABC}, \mathrm{GABC}$ and Best-So-Far ABC algorithms. Therefore, the performance accuracy of GBABC can be considered consistent. The ANN structure is based on Dimension (D) value which represents the number of input layer (with nodes), hidden Layer (with nodes), biases values and output node as well. The best MSE training results when $\mathrm{CS}=8, \mathrm{D}=13$ and $\mathrm{C}=1.0, \mathrm{CS}=10, \mathrm{D}=21$ and $\mathrm{C}=1.2$ and $\mathrm{CS}=10$, $\mathrm{D}=21$ and $\mathrm{C}=1.2$ are given in Tables IX, $\mathrm{X}$ and XI. The BestSo-Far and proposed methods obtained the best MSE training error from $\mathrm{ABC}$ and $\mathrm{GABC}$ algorithms when $\mathrm{CS}=10, \mathrm{D}=21$ and $\mathrm{C}=1.5$ and $7,8,9$ hidden nodes. 
TABLE IV. AVERAge MSE Training For CRUde Oil Prices PREDICTION

\begin{tabular}{|l|l|l|l|l|}
\hline $\begin{array}{l}\text { NN } \\
\text { Structure }\end{array}$ & ABC & GABC & Best-So-Far & GBABC \\
\hline $\mathbf{4 - 2 - 1}$ & 0.001234 & $1.16 \mathrm{E}-03$ & $9.73 \mathrm{E}-05$ & $\mathbf{3 . 1 7 E - 0 7}$ \\
\hline $\mathbf{4 - 3 - 1}$ & 0.001202 & $1.61 \mathrm{E}-03$ & $9.26 \mathrm{E}-05$ & $\mathbf{3 . 9 9 E - 0 7}$ \\
\hline $\mathbf{4 - 4 - 1}$ & 0.001034 & $1.09 \mathrm{E}-03$ & $9.80 \mathrm{E}-05$ & $\mathbf{3 . 1 2 E}-09$ \\
\hline $\mathbf{4 - 5 - 1}$ & 0.001042 & $1.01 \mathrm{E}-03$ & $7.65 \mathrm{E}-05$ & $\mathbf{1 . 3 9 E - 0 9}$ \\
\hline $\mathbf{4 - 6 - 1}$ & 0.000836 & $1.23 \mathrm{E}-04$ & $4.53 \mathrm{E}-05$ & $\mathbf{1 . 0 2 E - 0 9}$ \\
\hline $\mathbf{4 - 7 - 1}$ & 0.000491 & $1.01 \mathrm{E}-04$ & $3.01 \mathrm{E}-05$ & $\mathbf{1 . 0 1 E - 0 9}$ \\
\hline $\mathbf{4 - 8 - 1}$ & 0.000402 & $9.81 \mathrm{E}-05$ & $\mathbf{1 . 1 0 E}-08$ & $\mathbf{8 . 1 1 E}-10$ \\
\hline $\mathbf{4 - 9 - 1}$ & 0.000371 & $7.12 \mathrm{E}-05$ & $\mathbf{3 . 9 3 E}-06$ & $\mathbf{3 . 1 3 E}-11$ \\
\hline
\end{tabular}

Table XI and XII contains the best NMSE and MSE out of sample for oil prices prediction when $C S=10, D=21$ and $C=1.2$ and $C S=10, D=21$ and $C=1.2$. From these tables, the error is rapidly decreasing when the numbers of hidden nodes are decreasing.

TABLE V. Average NMSE for CRUde OIL Prices Prediction

\begin{tabular}{|l|l|l|l|l|}
\hline $\begin{array}{l}\text { NN } \\
\text { Structure }\end{array}$ & ABC & GABC & Best-So-Far & GBABC \\
\hline $\mathbf{4 - 2 - 1}$ & 0.001131 & $1.16 \mathrm{E}-04$ & $1.07 \mathrm{E}-06$ & $\mathbf{1 . 0 1 E - 0 7}$ \\
\hline $\mathbf{4 - 3 - 1}$ & 0.001044 & $1.61 \mathrm{E}-04$ & $1.93 \mathrm{E}-06$ & $\mathbf{1 . 2 0 E - 0 8}$ \\
\hline $\mathbf{4 - 4 - 1}$ & 0.001012 & $1.09 \mathrm{E}-04$ & $3.18 \mathrm{E}-06$ & $\mathbf{3 . 1 2 E - 0 9}$ \\
\hline $\mathbf{4 - 5 - 1}$ & 0.001042 & $1.01 \mathrm{E}-04$ & $4.77 \mathrm{E}-06$ & $\mathbf{1 . 3 9 E - 0 9}$ \\
\hline $\mathbf{4 - 6 - 1}$ & 0.000498 & $1.02 \mathrm{E}-04$ & $6.45 \mathrm{E}-06$ & $\mathbf{1 . 0 7 E - 0 9}$ \\
\hline $\mathbf{4 - 7 - 1}$ & 0.000209 & $1.01 \mathrm{E}-05$ & $\mathbf{1 . 0 2 E - 0 7}$ & $1.00 \mathrm{E}-06$ \\
\hline $\mathbf{4 - 8 - 1}$ & 0.000329 & $1.08 \mathrm{E}-05$ & $1.82 \mathrm{E}-06$ & $\mathbf{1 . 8 1 E - 1 0}$ \\
\hline $\mathbf{4 - 9 - 1}$ & 0.000109 & $8.71 \mathrm{E}-06$ & $3.73 \mathrm{E}-07$ & $\mathbf{3 . 9 3 E - 1 1}$ \\
\hline
\end{tabular}

TABLE VI. AVERAge MSE OUt OF SAMPLES For CRUde OIL Prices PREDICTION

\begin{tabular}{|l|l|l|l|l|}
\hline $\begin{array}{l}\text { NN } \\
\text { Structure }\end{array}$ & ABC & GABC & Best-So-Far & GBABC \\
\hline $\mathbf{4 - 2 - 1}$ & $3.20 \mathrm{E}-05$ & $1.83 \mathrm{E}-06$ & $9.99 \mathrm{E}-06$ & $\mathbf{9 . 9 9 E - 0 8}$ \\
\hline $\mathbf{4 - 3 - 1}$ & $3.10 \mathrm{E}-06$ & $9.12 \mathrm{E}-05$ & $9.81 \mathrm{E}-06$ & $\mathbf{8 . 1 2 E}-08$ \\
\hline $\mathbf{4 - 4 - 1}$ & $2.01 \mathrm{E}-03$ & $8.13 \mathrm{E}-05$ & $1.92 \mathrm{E}-06$ & $\mathbf{8 . 0 0 E}-08$ \\
\hline $\mathbf{4 - 5 - 1}$ & $1.10 \mathrm{E}-05$ & $9.22 \mathrm{E}-06$ & $\mathbf{1 . 2 3 E}-07$ & $9.05 \mathrm{E}-07$ \\
\hline $\mathbf{4 - 6 - 1}$ & $1.09 \mathrm{E}-05$ & $9.11 \mathrm{E}-06$ & $9.78 \mathrm{E}-07$ & $\mathbf{2 . 0 0 E - 0 8}$ \\
\hline $\mathbf{4 - 7 - 1}$ & $2.76 \mathrm{E}-05$ & $1.90 \mathrm{E}-06$ & $\mathbf{1 . 9 3 E - 0 8}$ & $1.91 \mathrm{E}-07$ \\
\hline $\mathbf{4 - 8 - 1}$ & $3.12 \mathrm{E}-05$ & $3.00 \mathrm{E}-06$ & $7.92 \mathrm{E}-06$ & $\mathbf{9 . 0 1 E - 0 9}$ \\
\hline $\mathbf{4 - 9 - 1}$ & $2.01 \mathrm{E}-05$ & $1.59 \mathrm{E}-06$ & $9.46 \mathrm{E}-06$ & $\mathbf{1 . 8 2 E - 1 0}$ \\
\hline
\end{tabular}

TABLE VII. AVERAge ACCURACY FOR CRUde OIL PricEs PREDICTION

\begin{tabular}{|l|l|l|l|l|}
\hline $\begin{array}{l}\text { NNs } \\
\text { Structure }\end{array}$ & ABC & GABC & Best-So-Far & GBABC \\
\hline $\mathbf{4 - 5 - 1}$ & 90.13 & 93.72 & 95.74 & $\mathbf{9 7 . 9 8}$ \\
\hline $\mathbf{4 - 6 - 1}$ & 91.01 & 92.24 & 96.92 & $\mathbf{9 8 . 7 0}$ \\
\hline $\mathbf{4 - 7 - 1}$ & 90.38 & 94.81 & 96.27 & $\mathbf{9 9 . 1 5}$ \\
\hline $\mathbf{4 - 8 - 1}$ & 91.63 & 94.78 & 96.31 & $\mathbf{9 9 . 1 0}$ \\
\hline $\mathbf{4 - 9 - 1}$ & 92.12 & 94.31 & $\mathbf{9 8 . 3 5}$ & 98.17 \\
\hline
\end{tabular}

TABLE VIII. SucCess RATE OF All LEARNING AlgORIthMS FOR CRUDE OIL PRICES PREDICTION

\begin{tabular}{|l|l|l|l|l|}
\hline $\begin{array}{l}\text { NN } \\
\text { Structure }\end{array}$ & ABC & GABC & Best-So-Far & GBABC \\
\hline $\mathbf{4 - 2 - 1}$ & $80 \%$ & $87 \%$ & $98 \%$ & $\mathbf{1 0 0 \%}$ \\
\hline $\mathbf{4 - 6 - 1}$ & $95 \%$ & $98 \%$ & $\mathbf{1 0 0} \%$ & $\mathbf{1 0 0 \%}$ \\
\hline $\mathbf{4 - 7 - 1}$ & $89 \%$ & $\mathbf{1 0 0} \%$ & $\mathbf{1 0 0} \%$ & $\mathbf{1 0 0} \%$ \\
\hline $\mathbf{4 - 8 - 1}$ & $\mathbf{1 0 0} \%$ & $\mathbf{1 0 0} \%$ & $\mathbf{1 0 0} \%$ & $\mathbf{1 0 0} \%$ \\
\hline $\mathbf{4 - 9 - 1}$ & $\mathbf{1 0 0} \%$ & $\mathbf{1 0 0} \%$ & $\mathbf{1 0 0} \%$ & $\mathbf{1 0 0} \%$ \\
\hline
\end{tabular}

TABLE IX. Best MSE TRAINING For CRUde OIL PRICES PREdiction WHEN $\mathrm{CS}=8, \mathrm{D}=13$ AND $\mathrm{C}=1.0$

\begin{tabular}{|l|l|l|l|l|}
\hline $\begin{array}{l}\text { NN } \\
\text { Structure }\end{array}$ & ABC & GABC & Best-So-Far & GBABC \\
\hline $\mathbf{4 - 2 - 1}$ & 0.0012001 & $5.16 \mathrm{E}-03$ & $8.13 \mathrm{E}-05$ & $\mathbf{2 . 1 2 E - 0 6}$ \\
\hline $\mathbf{4 - 3 - 1}$ & 0.0011915 & $1.10 \mathrm{E}-03$ & $4.24 \mathrm{E}-05$ & $\mathbf{3 . 1 5 E}-07$ \\
\hline $\mathbf{4 - 4 - 1}$ & 0.0010021 & $3.10 \mathrm{E}-03$ & $2.50 \mathrm{E}-04$ & $\mathbf{2 . 1 8 E - 0 6}$ \\
\hline $\mathbf{4 - 5 - 1}$ & 0.0009323 & $1.01 \mathrm{E}-04$ & $1.65 \mathrm{E}-05$ & $\mathbf{1 . 5 9 E - 0 7}$ \\
\hline $\mathbf{4 - 6 - 1}$ & 0.0008102 & $3.27 \mathrm{E}-04$ & $3.34 \mathrm{E}-05$ & $\mathbf{4 . 0 8 E - 0 8}$ \\
\hline $\mathbf{4 - 7 - 1}$ & 0.0000961 & $1.02 \mathrm{E}-05$ & $\mathbf{3 . 0 1 E - 0 7}$ & $\mathbf{1 . 1 6 E - 0 8}$ \\
\hline $\mathbf{4 - 8 - 1}$ & 0.0001223 & $9.21 \mathrm{E}-05$ & $\mathbf{1 . 1 0 E}-08$ & $\mathbf{6 . 1 5 E}-08$ \\
\hline $\mathbf{4 - 9 - 1}$ & $\mathbf{0 . 0 0 0 1 0 0 2}$ & $\mathbf{7 . 1 2 E}-06$ & $\mathbf{2 . 9 3 E - 0 6}$ & $\mathbf{8 . 1 2 E - 0 9}$ \\
\hline
\end{tabular}

TABLE X. Best MSE TRAining FOR CRUde OIL PRICES PREDiction WHEN $\mathrm{CS}=10, \mathrm{D}=21$ AND $\mathrm{C}=1.2$

\begin{tabular}{|l|l|l|l|l|}
\hline $\begin{array}{l}\text { NN } \\
\text { Structure }\end{array}$ & ABC & GABC & Best-So-Far & GBABC \\
\hline $\mathbf{4 - 2 - 1}$ & 0.0001281 & $2.10 \mathrm{E}-04$ & $1.10 \mathrm{E}-05$ & $8.72 \mathrm{E}-06$ \\
\hline $\mathbf{4 - 3 - 1}$ & 0.0013123 & $3.04 \mathrm{E}-04$ & $2.84 \mathrm{E}-06$ & $6.95 \mathrm{E}-07$ \\
\hline $\mathbf{4 - 4 - 1}$ & 0.0001902 & $3.05 \mathrm{E}-04$ & $3.56 \mathrm{E}-06$ & $5.17 \mathrm{E}-07$ \\
\hline $\mathbf{4 - 5 - 1}$ & 0.0009091 & $4.05 \mathrm{E}-04$ & $3.84 \mathrm{E}-06$ & $1.09 \mathrm{E}-07$ \\
\hline $\mathbf{4 - 6 - 1}$ & 0.0001230 & $2.01 \mathrm{E}-04$ & $4.54 \mathrm{E}-06$ & $\mathbf{4 . 0 8 E - 0 7}$ \\
\hline $\mathbf{4 - 7 - 1}$ & 0.0001294 & $\mathbf{1 . 0 2 E}-06$ & $\mathbf{6 . 0 1 E}-07$ & $\mathbf{7 . 0 6 E - 0 7}$ \\
\hline $\mathbf{4 - 8 - 1}$ & $\mathbf{0 . 0 0 0 1 9 2 8}$ & $\mathbf{3 . 2 3 E - 0 6}$ & $\mathbf{8 . 1 0 E}-07$ & $\mathbf{3 . 1 0 E}-07$ \\
\hline $\mathbf{4 - 9 - 1}$ & $\mathbf{7 . 0 5 E - 0 5}$ & $\mathbf{7 . 1 2 E - 0 6}$ & $\mathbf{9 . 9 3 E - 0 7}$ & $\mathbf{3 . 1 0 E}-08$ \\
\hline
\end{tabular}

TABLE XI. Best NMSE TESTING FOR CRUde OIL Prices PREDiction WHEN $\mathrm{CS}=10, \mathrm{D}=21$ AND $\mathrm{C}=1.2$

\begin{tabular}{|l|l|l|l|l|}
\hline $\begin{array}{l}\text { NN } \\
\text { Structure }\end{array}$ & ABC & GABC & $\begin{array}{l}\text { Best-So- } \\
\text { Far }\end{array}$ & GBABC \\
\hline $\mathbf{4 - 2 - 1}$ & 0.001081 & $1.16 \mathrm{E}-05$ & $1.07 \mathrm{E}-06$ & $1.21 \mathrm{E}-07$ \\
\hline $\mathbf{4 - 3}-1$ & 0.000131 & $1.61 \mathrm{E}-05$ & $1.73 \mathrm{E}-06$ & $1.30 \mathrm{E}-08$ \\
\hline $\mathbf{4 - 4 - 1}$ & 0.000105 & $1.09 \mathrm{E}-05$ & $3.18 \mathrm{E}-06$ & $3.10 \mathrm{E}-09$ \\
\hline $\mathbf{4 - 5}-1$ & 0.000118 & $1.01 \mathrm{E}-05$ & $4.17 \mathrm{E}-06$ & $1.30 \mathrm{E}-09$ \\
\hline $\mathbf{4 - 6 - 1}$ & 0.000290 & $1.02 \mathrm{E}-06$ & $6.40 \mathrm{E}-07$ & $1.09 \mathrm{E}-09$ \\
\hline $\mathbf{4 - 7 - 1}$ & $\mathbf{0 . 0 0 0 8 2 9}$ & $\mathbf{1 . 0 1 E}-06$ & $\mathbf{1 . 0 3 E - 0 7}$ & $\mathbf{1 . 0 0 E - 1 2}$ \\
\hline $\mathbf{4 - 8 - 1}$ & $\mathbf{0 . 0 0 0 1 2 8}$ & $\mathbf{1 . 0 8 E}-06$ & $\mathbf{1 . 3 2 E}-08$ & $\mathbf{1 . 8 1 E - 1 2}$ \\
\hline $\mathbf{4 - 9 - 1}$ & $\mathbf{0 . 0 0 0 0 1 7}$ & $\mathbf{8 . 7 1 E - 0 7}$ & $\mathbf{3 . 2 3 E - 0 8}$ & $\mathbf{3 . 9 3 E - 1 3}$ \\
\hline
\end{tabular}

TABLE XII. BeST OUT OF SAMPLE FOR CRUde OIL PRICES PREDICTION WHEN $\mathrm{CS}=10, \mathrm{D}=21$ AND $\mathrm{C}=1.2$

\begin{tabular}{|l|l|l|l|l|}
\hline $\begin{array}{l}\text { NN } \\
\text { Structure }\end{array}$ & ABC & GABC & Best-So-Far & GBABC \\
\hline $\mathbf{4 - 2 - 1}$ & $1.09 \mathrm{E}-03$ & $1.09 \mathrm{E}-05$ & $1.09 \mathrm{E}-04$ & $1.09 \mathrm{E}-06$ \\
\hline $\mathbf{4 - 3}-1$ & $9.12 \mathrm{E}-04$ & $9.12 \mathrm{E}-05$ & $9.12 \mathrm{E}-04$ & $9.12 \mathrm{E}-06$ \\
\hline $\mathbf{4 - 4 - 1}$ & $\mathbf{9 . 7 8 E - 0 4}$ & $\mathbf{9 . 7 8 E}-05$ & $\mathbf{9 . 7 8 E - 0 5}$ & $\mathbf{9 . 7 8 E - 0 6}$ \\
\hline $\mathbf{4 - 5}-1$ & $\mathbf{2 . 0 0 E - 0 5}$ & $\mathbf{2 . 0 0 E}-06$ & $\mathbf{2 . 0 0 E - 0 6}$ & $\mathbf{2 . 0 0 E - 0 8}$ \\
\hline $\mathbf{4 - 6 - 1}$ & $2.00 \mathrm{E}-05$ & $2.00 \mathrm{E}-06$ & $2.00 \mathrm{E}-06$ & $2.00 \mathrm{E}-08$ \\
\hline $\mathbf{4 - 7 - 1}$ & $2.36 \mathrm{E}-04$ & $2.36 \mathrm{E}-07$ & $2.36 \mathrm{E}-06$ & $\mathbf{2 . 3 6 E - 0 8}$ \\
\hline $\mathbf{4 - 8 - 1}$ & $\mathbf{9 . 9 9 E - 0 6}$ & $\mathbf{9 . 9 9 E - 0 7}$ & $\mathbf{9 . 9 9 E - 0 6}$ & $\mathbf{9 . 9 9 E - 1 0}$ \\
\hline $\mathbf{4 - 9 - 1}$ & $\mathbf{7 . 1 2 E - 0 5}$ & $\mathbf{7 . 1 2 E}-07$ & $\mathbf{7 . 1 2 E}-06$ & $\mathbf{7 . 1 2 E}-10$ \\
\hline $\mathbf{4 - 9 - 1}$ & $2.76 \mathrm{E}-05$ & $\mathbf{2 . 7 6 E - 0 7}$ & $\mathbf{2 . 7 6 E - 0 7}$ & $\mathbf{2 . 7 6 E - 1 1}$ \\
\hline
\end{tabular}

TABLE XIII. Average MAPE for CRUde OIL Prices Prediction

\begin{tabular}{|l|l|l|l|l|}
\hline $\begin{array}{l}\text { NN } \\
\text { Structure }\end{array}$ & ABC & GABC & Best-So-Far & GBABC \\
\hline $\mathbf{4 - 2 - 1}$ & 0.0015 & 0.00139 & $\mathbf{0 . 0 0 0 1 0 2}$ & $\mathbf{0 . 0 0 0 1 0 7}$ \\
\hline $\mathbf{4 - 3 - 1}$ & 0.00431 & $1.30 \mathrm{E}-03$ & $\mathbf{4 . 3 1 E - 0 6}$ & $\mathbf{1 . 2 1 E - 0 7}$ \\
\hline $\mathbf{4 - 4 - 1}$ & 0.00273 & $1.01 \mathrm{E}-03$ & $\mathbf{9 . 1 0 E - 0 5}$ & $\mathbf{3 . 0 0 E}-08$ \\
\hline $\mathbf{4 - 5}-1$ & 0.00383 & $1.00 \mathrm{E}-03$ & $\mathbf{7 . 0 1 E - 0 5}$ & $\mathbf{1 . 0 2 E - 0 9}$ \\
\hline $\mathbf{4 - 6 - 1}$ & 0.00091 & $1.01 \mathrm{E}-04$ & $\mathbf{4 . 3 5 E - 0 5}$ & $\mathbf{1 . 0 1 E - 0 9}$ \\
\hline $\mathbf{4 - 7 - 1}$ & 0.00022 & $1.00 \mathrm{E}-04$ & $\mathbf{3 . 0 0 E - 0 5}$ & $\mathbf{1 . 0 0 E - 0 9}$ \\
\hline $\mathbf{4 - 8}-1$ & 0.00041 & $9.21 \mathrm{E}-05$ & $\mathbf{1 . 0 0 E - 0 7}$ & $\mathbf{2 . 1 1 E - 1 0}$ \\
\hline
\end{tabular}


TABLE XIV. Average RMSE fOR CRUde OIL Prices Prediction

\begin{tabular}{|l|l|l|l|l|}
\hline $\begin{array}{l}\text { NN } \\
\text { Structure }\end{array}$ & ABC & GABC & Best-So-Far & GBABC \\
\hline $\mathbf{4 - 2 - 1}$ & 0.01131812 & 0.01449137 & 0.003316625 & 0.002952965 \\
\hline $\mathbf{4 - 3 - 1}$ & 0.03622568 & 0.01743559 & 0.00168523 & $\mathbf{0 . 0 0 0 8 3 3 6 6 7}$ \\
\hline $\mathbf{4 - 4 - 1}$ & 0.01379130 & 0.01746424 & 0.001886796 & $\mathbf{0 . 0 0 0 7 1 9 0 2 7}$ \\
\hline $\mathbf{4 - 5 - 1}$ & 0.03015128 & 0.02012461 & 0.001959592 & $\mathbf{0 . 0 0 0 3 3 0 1 5 1}$ \\
\hline $\mathbf{4 - 6 - 1}$ & 0.01109053 & 0.01417744 & 0.002130728 & $\mathbf{0 . 0 0 0 6 3 8 7 4 9}$ \\
\hline $\mathbf{4 - 7 - 1}$ & 0.01137541 & $\mathbf{0 . 0 0 1 0 0 9 9 5}$ & $\mathbf{0 . 0 0 0 7 7 5 2 4 2}$ & $\mathbf{0 . 0 0 0 8 4 0 2 3 8}$ \\
\hline $\mathbf{4 - 8 - 1}$ & 0.01388524 & $\mathbf{0 . 0 0 1 7 9 7 2 2}$ & $\mathbf{0 . 0 0 0 9 1 9 0 2}$ & $\mathbf{0 . 0 0 0 5 5 6 7 7 6}$ \\
\hline $\mathbf{4 - 9 - 1}$ & $\mathbf{0 . 0 0 8 3 9 6 4 2}$ & 0.00266833 & 0.000996494 & $\mathbf{0 . 0 0 0 1 7 6 0 6 8}$ \\
\hline
\end{tabular}

The average MAPE values obtained through the abovementioned methods for crude oil prices are shown in Table XIII. Among the various method, the proposed GBABC achieved the lowest (the best) values with more hidden nodes, while $\mathrm{ABC}$ and GABC achieved the highest (the worst) values in average cases. The MAPE values obtained by Best-So-Far method are also lowest when compared with $\mathrm{ABC}$ and GABC algorithms.

The values of RMSE obtained by ABC, GABC, Best-SoFar and proposed GBABC algorithms are mentioned in Table XIV. In term of RMSE values, the typical two methods (GABC and Best-So-Far) and particularly GBABC algorithm obtained the highest numbers of minimum error values for the prediction of crude oil prices.

The best average simulation results using all abovementioned algorithms for crude oil price prediction are given Fig. 7 to 15 , respectively. The analysis of original and predict prices has presented in convergence, training and out of sample testing figures. Different values of the dimension, hidden layer nodes $\mathrm{C}$ and colony size have obtained different prediction results. From the following figures, $\mathrm{ABC}$ and $\mathrm{GABC}$ are not stable in convergence speed while Best so far and GBABC have fast convergence speed.

From Fig. 7, 8 and 9, the proposed GBABC converged quickly, which signifies that the proposed method is robust, promising and effective in the prediction of crude oil prices. The ABC and GABC algorithms are failed to convergence quickly as given in Fig. 7. The Best-So-Far method also fails to convergence quickly with dimension value 41 as shown in Fig. 9, means that GABC, ABC, and Best-So-Far are not stable in convergence speed for crude oil rice prediction. The GBABC has very fast conversion speed when $D=21,35$ and 41 and colony size is 7 and 9.

Using the above bio inspired learning techniques explore the best values of weights of each connection in order to reduce the training error for the crude oil prices prediction task. After repeating this process for a sufficiently large number of learning cycles the network will usually converge to any state, where the error of the calculations is small with high predicted performance. The prediction curves on $75 \%$ dataset during training phase are given in Fig. 10, 12, 13, 14 and 15 with different D, CS and C values.

In case of $\mathrm{ABC}, \mathrm{GABC}$ and Best-So-Far methods, the predicted signal are not close and stable to original; these methods did not success to predict the future crude oil prices as shown in Fig. 10, 11 and 12, respectively. However, Fig. 13 and 15 are clearly showing that crude oil prices predicted by the GBABC algorithm are very close to actual oil prices.
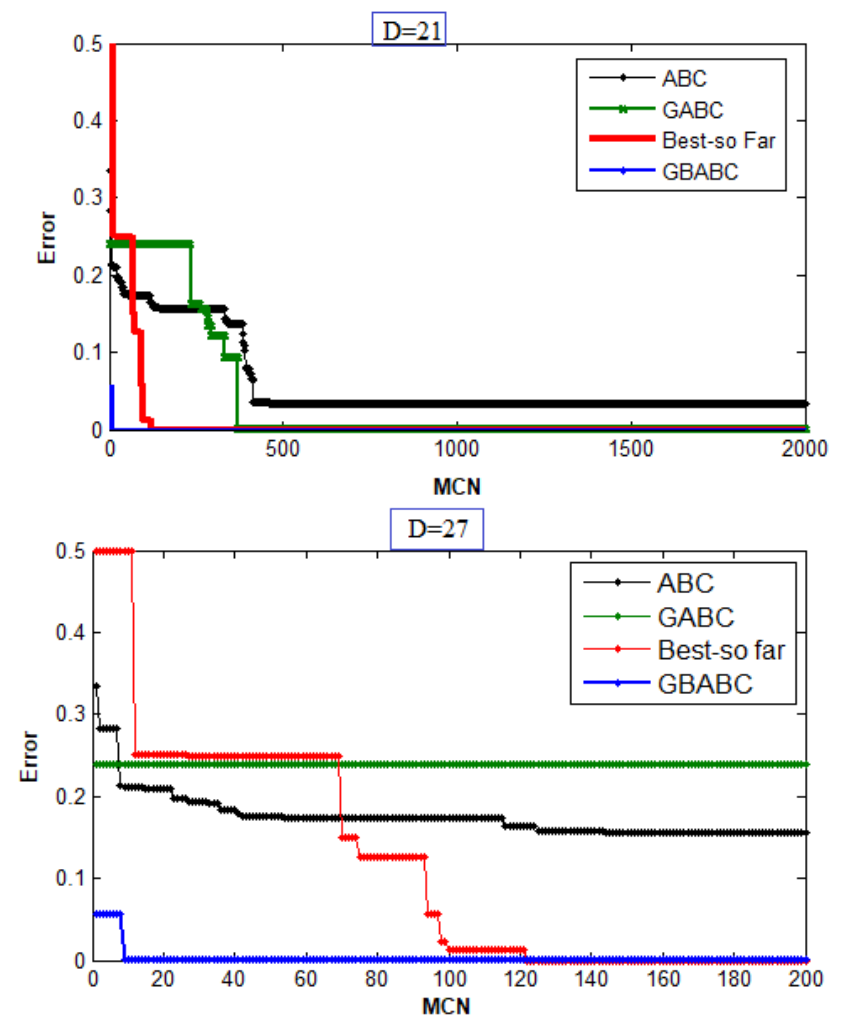

Fig 7. Average convergence curves of typical and proposed algorithm (CS=8 and Limit 10).
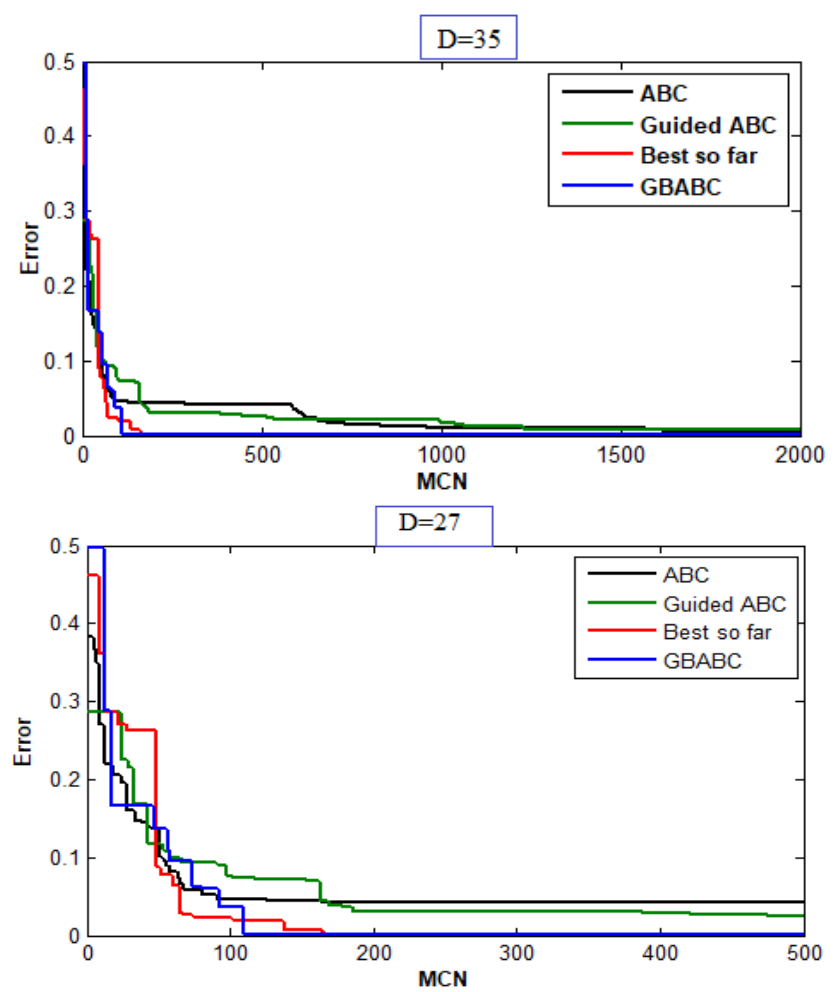

Fig 8. Average convergence curves of typical and proposed algorithm ( $\mathrm{CS}=10$ and Limit 20). 

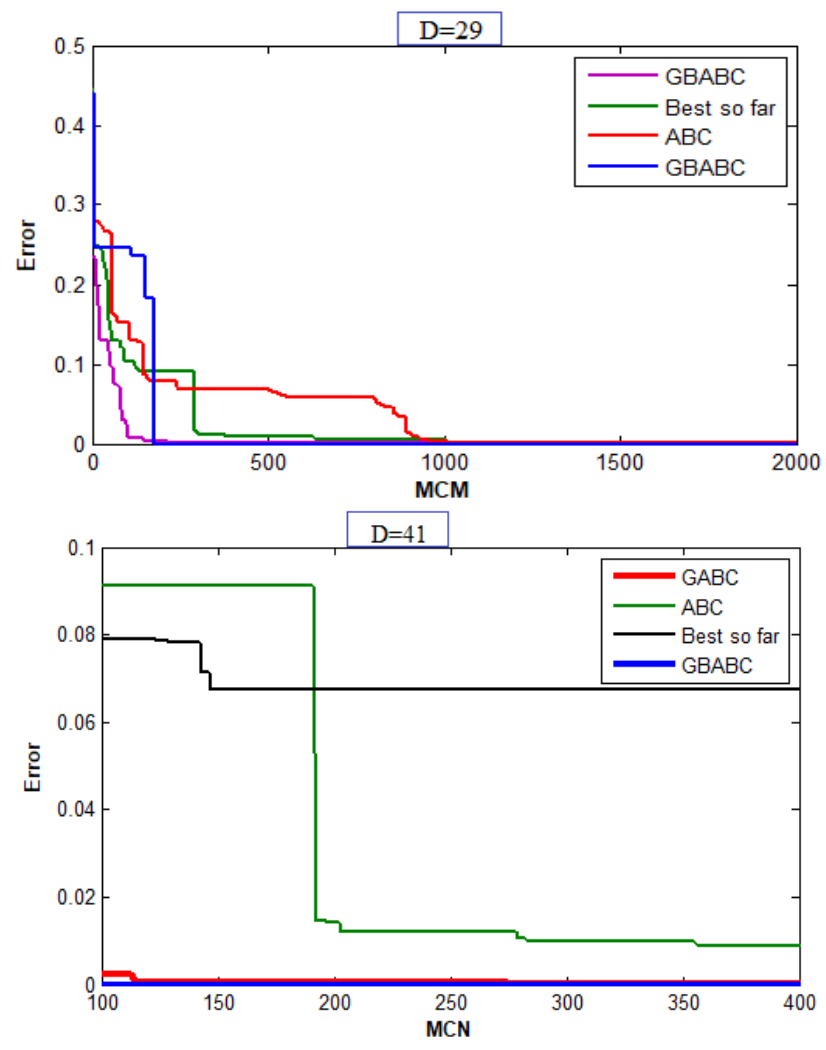

Fig 9. Average convergence curves of typical and proposed algorithms $(\mathrm{CS}=10$, limit $10 \& 20)$.
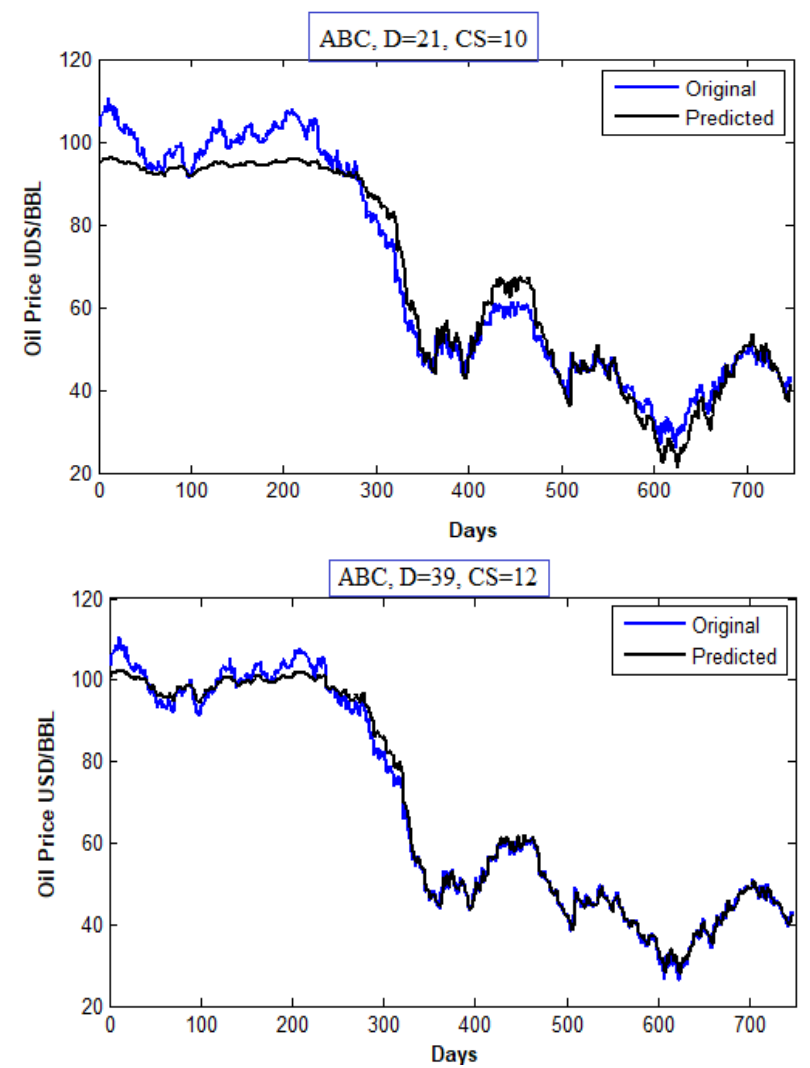

Fig 10. Best average prediction Curves by $\mathrm{ABC}$ of crude oil prices prediction (limit 10 \& 15).
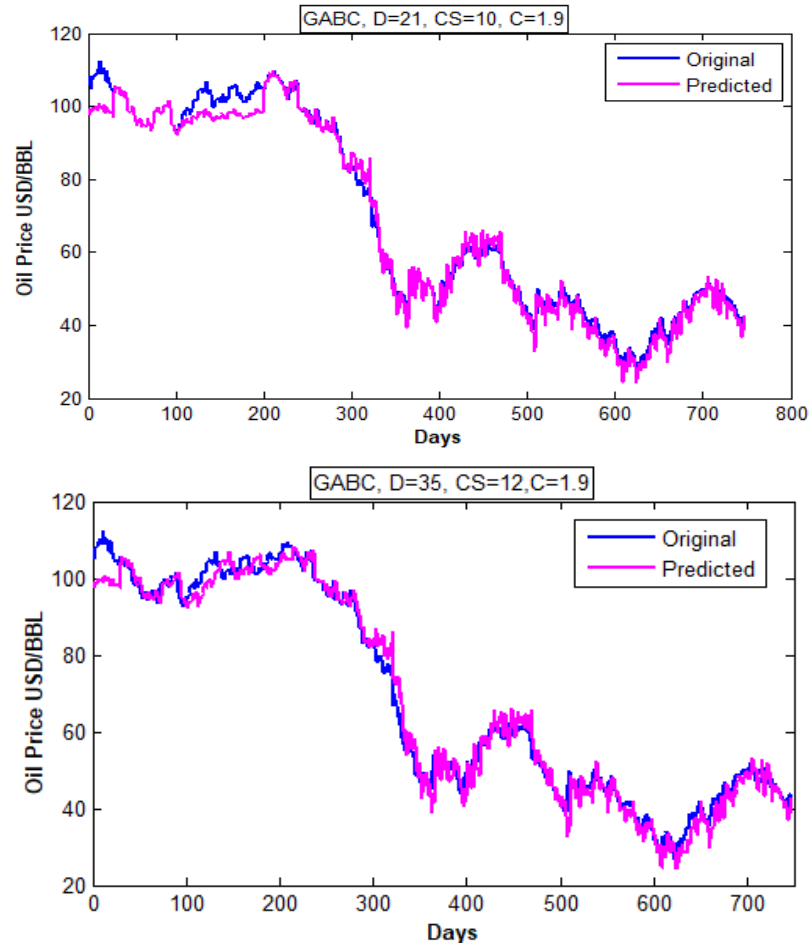

Fig 11. Best average Curves by GABC of crude oil prices prediction (limit $10 \& 15)$.
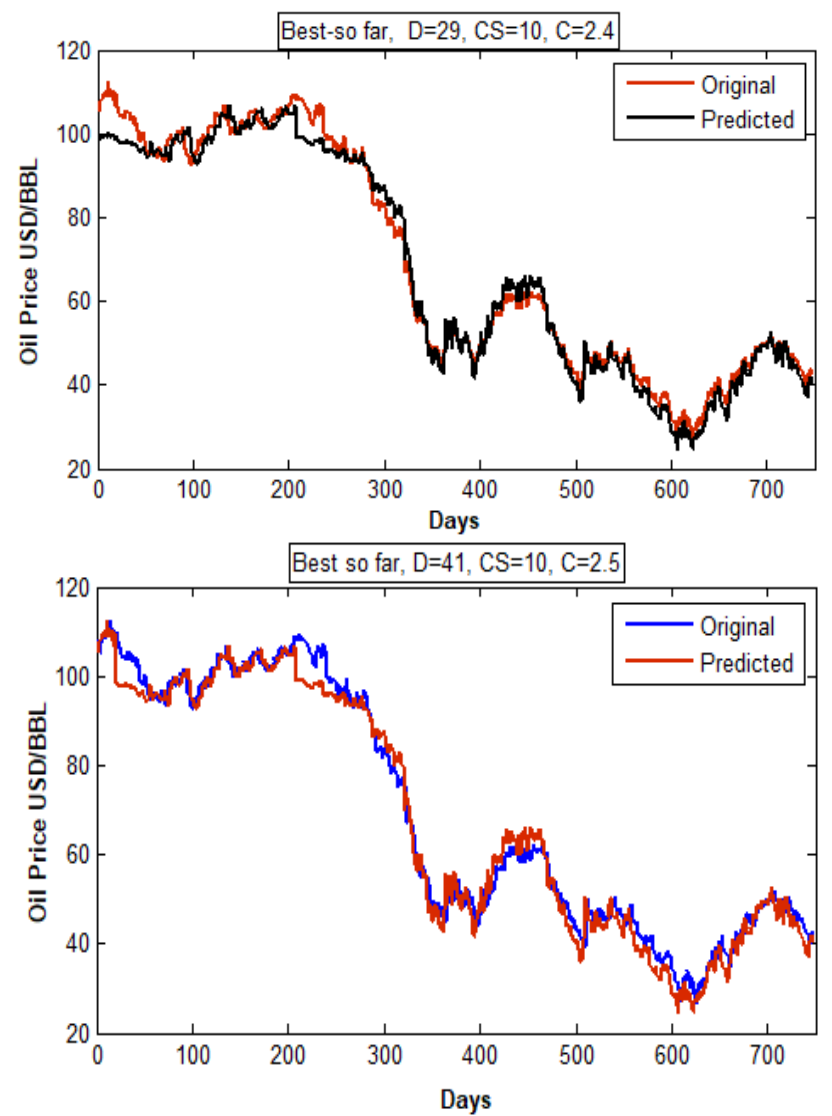

Fig 12. Best average Curves by Best-So-Far ABC of crude oil prices prediction (limit $10 \& 20$ ). 

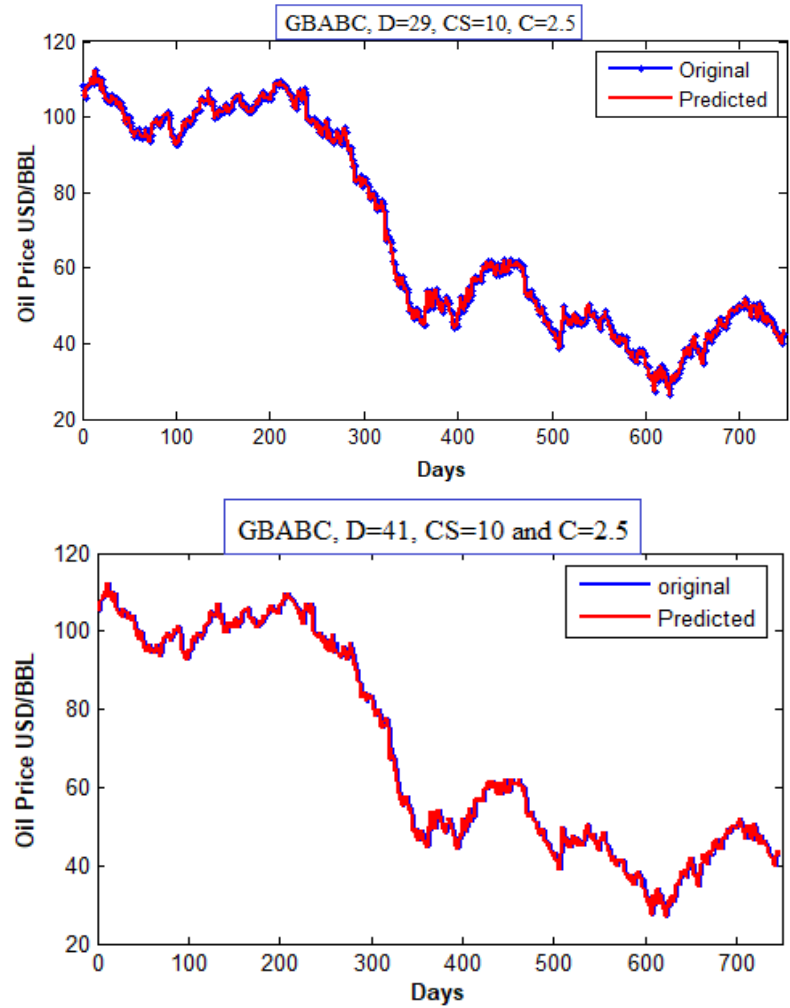

Fig 13. Best average prediction Curves by GBABC of crude oil prices (limit 20 for both).
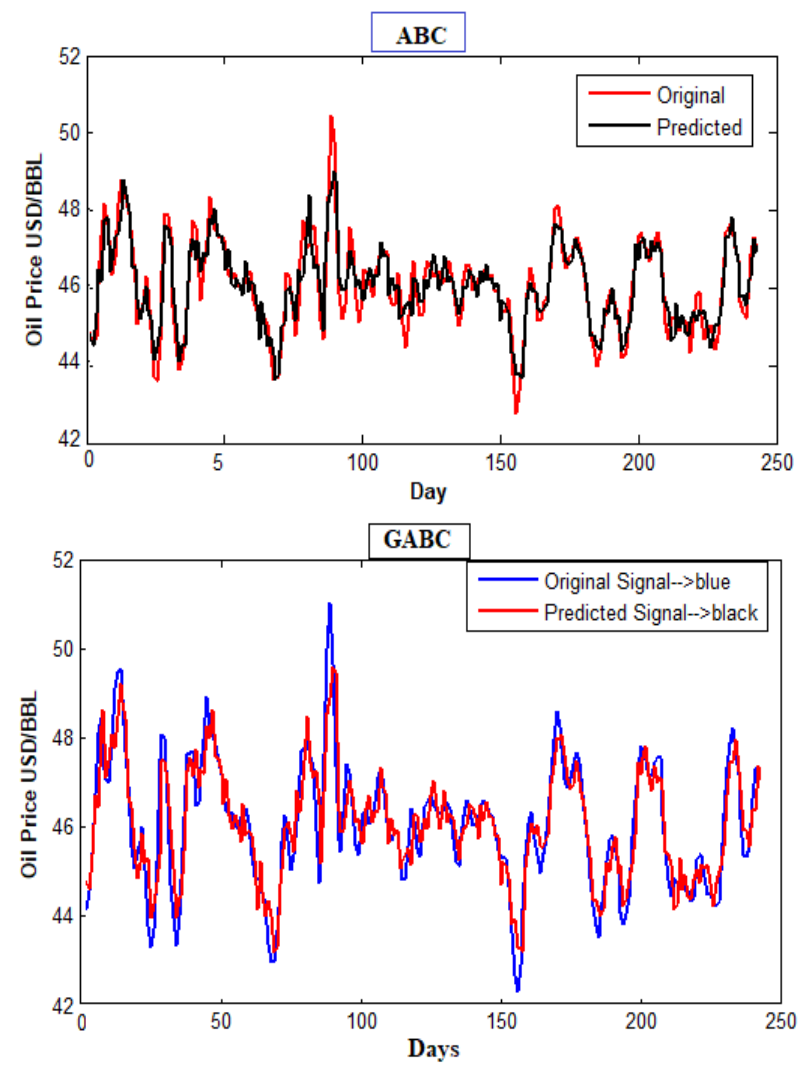

Fig 14. Best average prediction curves out of sample by $A B C$ and $G A B C$ algorithms (limit 20 \& 10)
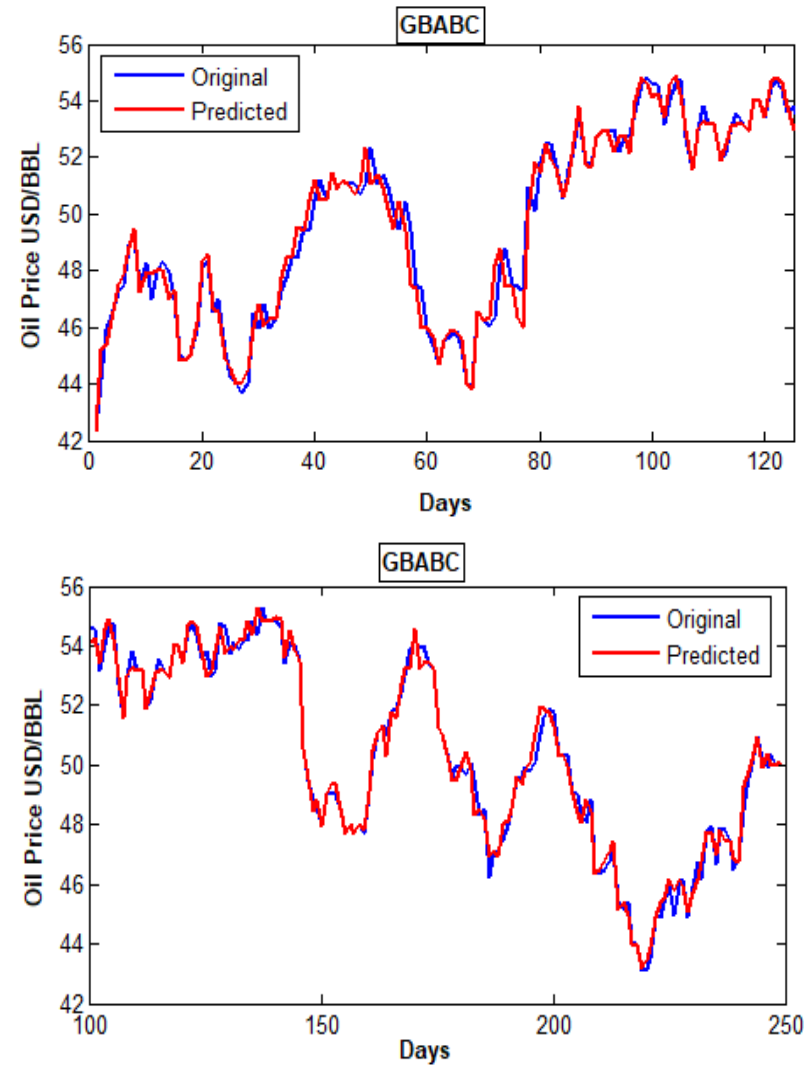

Fig 15. Best average prediction curves out of sample by GBABC algorithm (limit 15 \& 20).

The explored weight values have used to test GBABC performance on FFNN with the rest $25 \%$ dataset of crude oil price. The best average crude oil prediction curves out of samples have presented in Fig. 14 and 15. Again, the proposed GBABC algorithm predicted prices are very close to the original crude oil prices with different FFNN structures. From the above-mentioned all tables values and figures, the performance of the proposed GBABC algorithm success to reach to minim training and testing, prediction error, fast convergence, high success rate, and high prediction accuracy for crude oil prices. Based on the above simulation results and analysis, the proposed $\mathrm{GBABC}$ algorithm has the capability to predict the accurate future crude oil prices. Based upon on the above-mentioned proposed bio inspired GBABC algorithm outstanding simulation, the Saudi Arabia crude oil price can be easily predicted based on the past values.

From the abovementioned tables and figures, the prediction results have been affected through the control parameters specially colony size and limit. In $\mathrm{ABC}$, the best values found for the crude oil prices prediction were limit 10 and 15, CS 10 and 12 and $\mathrm{D}=21$ and 39 as shown in the abovementioned figures and tables. For the proposed GBABC algorithm, the best control parameters values were limit 20, D 29 and 41 and CS 10 as mentioned in the simulation results. The proper selection of the control parameters can increase the effectiveness of the ABC, GABC, Best So far and GBABC algorithms. 
TABLE XV. Null Hypothesis SignificANT Test AMONG THE ORIGINAL AND PREDICTED OIL PRICES

\begin{tabular}{|c|c|c|c|c|c|c|}
\hline Groups & Count & Sum & Average & Variance & & \\
\hline Actual Dataset & 200 & 20044.5 & 100.223 & 18.1112 & & \\
\hline Predicted by GBABC & 200 & 20022.8 & 100.1400 & 18.1002 & & \\
\hline Predicted by ABC & 200 & 19756.9 & 98.7845 & 17.2231 & & \\
\hline Predicted by Best So Far & 200 & 20001.5 & 100.0075 & 17.9151 & & \\
\hline Predicted by GABC & 200 & 19826.5 & 99.1325 & 16.1102 & & \\
\hline \multicolumn{7}{|l|}{ ANOVA } \\
\hline Source of Variation & $S S$ & $d f$ & $M S$ & $\boldsymbol{F}$ & $P$-value & F crit \\
\hline Between Groups & 245.786 & 4 & 61.4464 & 3.38183 & 0.00928 & 2.38088 \\
\hline Within Groups & 18078.7 & 995 & 18.1696 & & & \\
\hline Total & 18324.5 & 999 & & & & \\
\hline
\end{tabular}

TABLE XVI. F-TEST TwO-SAMPLE FOR VARIANCES

\begin{tabular}{|l|l|l|}
\hline & Original Prices Dataset & Predicted by GBABC \\
\hline Mean & 100.2225 & 99.98792 \\
\hline Variance & 18.11023 & 17.98520 \\
\hline Observations & 200 & 200 \\
\hline df & 199 & 198 \\
\hline F & 1.027519027 & \\
\hline P(F $<$ f) one-tail & 0.494170446 & \\
\hline F Critical one-tail & 1.263340341 & \\
\hline
\end{tabular}

The results obtained by these four algorithms were tested using the Null Hypothesis Significance Testing (NHST) to know the significant similarity of the proposed and typical algorithms for crude oil prices prediction tasks. In this regards, the original dataset of the first 200 days were selected to know the critical difference. The selected dataset were compared with the results obtained by $\mathrm{ABC}, \mathrm{GABC}$, Best so far $\mathrm{ABC}$ and proposed GBABC algorithms. The results obtained with the $200 \mathrm{MCN}, \mathrm{C} 1$ and $\mathrm{C} 2$ (1.5 and 2.5), Limit 20, CS=30, D=23 and alpha $=0.05$ as given in the following Tables XV and XVI.

A part from MSE, NMSE, success rate and accuracy, the ANOVA test analysis of Tables XV and XVI shows the ratio of similarity/difference ratio between the original crude oil prices dataset and the predicted prices using $\mathrm{ABC}, \mathrm{GABC}$, GBABC and best so far ABC algorithms. Table XVI, where the overall original crude oil prices of the first 200 days, and the predicted crude oil prices through the typical and proposed method show that the proposed method GBABC algorithm along with ANN has a very least difference (in term of Sum, Average and Variances) in when compare to GABC, ABC and Best so far $\mathrm{ABC}$ algorithms. The mean and variance of the original prices and predicted prices by GBABC algorithm are much close as shown in the Table XV. Overall, the $\mathrm{p}$ value less than 0.5 so we reject the null hypothesis. We can then conclude that the average of the dependent variable is not the same for all methods. According to the ANOVA, if the null hypothesis is rejected, then all we know is that at least two methods:
$\mathrm{GABC}$ and $\mathrm{ABC}$ are different from each other and original as well.

Furthermore, the predicted prices obtained by Best so far methods are also close to the original crude oil prices. From Table XV, when the results obtained by the proposed GBABC algorithm analysis with original crude oil prices of the first 200 days, where again the original and predicted values are very close. Based on the $\mathrm{T}$ test, as shown that the $\mathrm{P}$ value is greater than 0.05 so the null hypothesis can't be rejected. This shows that the crude oil prices obtained by the proposed method are very close to the actual prices' dataset

\section{CONCLUSION}

The FFNN was trained and tested through the bio inspired learning methods such as ABC, GABC, Best-So-Far and GBABC and it is a computer based mathematical simulation model that predicts high accurate crude oil prices. Different FFNN structures of hidden layer nodes with different learning methods, parameters such as CS, D and C values are used as given in Table III. The proposed GBABC algorithm performed well in term of MSE, NMSE, Accuracy and success rate. The convergence speed of GBABC method is faster than typical methods. Courtesy of the strong exploration and exploitation process, the proposed method has enough decreased global trapping problem based on guided employed bees, Best-So-Far onlooker and scout bees' strategies. Therefore, the proposed method has a high accuracy, less prediction error and high success rate. Thus, the proposed GBABC is a robust and 
efficient method for crude oil prices prediction. However, it is difficult to set the parameters of the proposed algorithm and ANN model appropriately. Based on high accurate predictions, the crude oil investors, analyst or producer can easily predict the volatility of the crude oil prices in different times and the environment as well. The GBABC algorithm can be extended to different application such as clustering, numerical function optimization and other complex problem solver.

\section{ACKNOWLEDGMENTS}

The authors would like to thanks Deanship of Scientific Research, King Khalid University, Abha Saudi Arabia for supporting this research under the project number 553 (1438).

\section{REFERENCES}

[1] V. Guerriero, S. Mazzoli, A. Iannace, S. Vitale, A. Carravetta, and C. Strauss, "A permeability model for naturally fractured carbonate reservoirs," Mar. Pet. Geol., vol. 40, pp. 115-134, 2013.

[2] J. Chamber, "Saudi Arabian Sector Report - Oil and Gas July 2015," Jeddah Chamber, Jeddah, Kingdom of Saudi Arabia, 2015.

[3] E. McAleavey., "Saudi Arabia oil and gas market to 2023," 2014.

[4] T. Economics, "Saudi Arabia Crude Oil Production," vol. 2017. 2017.

[5] Argaam, "Top 10 oil producing countries in the world in 2016," 2017.

[6] I. E. Agency, "Oil Market Report," Oil Market Report, vol. 2017. https://www.iea.org/, 2015.

[7] R. de Best, "Total OPEC crude oil production from 1998 to 2017 (in 1,000 barrels per day)," 2018. [Online]. Available: https://www.statista.com/chart/14298/black-and-gold/. [Accessed: 12Feb-2019].

[8] A. Shabri and R. Samsudin, "Crude Oil Price Forecasting Based on Hybridizing Wavelet Multiple Linear Regression Model, Particle Swarm Optimization Techniques, and Principal Component Analysis," Sci. World J., vol. 2014, p. 8, 2014.

[9] W. Xie, L. Yu, S. Xu, and S. Wang, "A New Method for Crude Oil Price Forecasting Based on Support Vector Machines," in Computational Science - ICCS 2006: 6th International Conference, Reading, UK, May 28-31, 2006, Proceedings, Part IV, V. N. Alexandrov, G. D. van Albada, P. M. A. Sloot, and J. Dongarra, Eds. Berlin, Heidelberg: Springer Berlin Heidelberg, 2006, pp. 444-451.

[10] O. of the P. E. Countries, "OPEC Crude Oil Price," vol. 2017. Organization of the Petroleum Exporting Countries, 2017.

[11] index mundi, "http://www.indexmundi.com/commodities/?commodity=crudeoil\&months $=60 . " 2016$.

[12] J. Hamilton, "What is an oil shock?," J. Econom., vol. 113, no. 2, pp. 363-398, 2003.

[13] P. K. Narayan, S. Sharma, W. C. Poon, and J. Westerlund, "Do oil prices predict economic growth? New global evidence," Energy Econ., vol. 41, pp. 137-146, 2014.

[14] I. Mundi, "Crude Oil Price." 2017.

[15] F. Fuels, "OPEC oil price annually 1960-2018," Statistical Report, 2019. [Online]. Available: https://www.statista.com/statistics/262858/changein-opec-crude-oil-prices-since-1960/. [Accessed: 02-Nov-2019].

[16] M. M. Mostafa and A. A. El-Masry, "Oil price forecasting using gene expression programming and artificial neural networks," Econ. Model, vol. 54, pp. 40-53, 2016.

[17] B. Abramson and A. Finizza, "Using belief networks to forecast oil prices,” Int. J. Forecast., vol. 7, no. 3, pp. 299-315, 1991.

[18] B. R. Das, S. Sahoo, C. S. Panda, and S. Patnaik, "Part of Speech Tagging in Odia Using Support Vector Machine," Procedia Comput. Sci., vol. 48, no. Supplement C, pp. 507-512, 2015.

[19] Z. Pawlak, "Rough sets," Int. J. Comput. Inf. Sci., 1982.

[20] J. J. Buckley and L. J. Jowers, "Fuzzy sets," Stud. Fuzziness Soft Comput., 2008.

[21] C. N. Babu and B. E. Reddy, "A moving-average filter based hybrid
ARIMA-ANN model for forecasting time series data," Appl. Soft Comput. J., 2014.

[22] A. Khashman and N. I. Nwulu, "Intelligent prediction of crude oil price using Support Vector Machines," in 2011 IEEE 9th International Symposium on Applied Machine Intelligence and Informatics (SAMI), 2011, pp. 165-169.

[23] M. Khashei and M. Bijari, "An artificial neural network (p,d,q) model for timeseries forecasting," Expert Syst. Appl., vol. 37, no. 1, pp. 479$489,2010$.

[24] M. a Otair and W. a Salameh, "Speeding Up Back-Propagation Neural Networks," Pros. 2005 Informing Sci. IT Educ. Jt. Conf. Speeding, 2005.

[25] P. D. McNelis et al., "Ant Colony Optimization," Neural Networks Financ., vol. 2, no. 1, p. 12, Dec. 2016.

[26] A. Panakkat and H. ADELI, "NEURAL NETWORK MODELS FOR EARTHQUAKE MAGNITUDE PREDICTION USING MULTIPLE SEISMICITY INDICATORS," Int. J. Neural Syst., vol. 17, no. 01, pp. 13-33, 2007.

[27] S. Dehuri, S. Patnaik, A. Ghosh, and R. Mall, "Application of elitist multi-objective genetic algorithm for classification rule generation," Appl. Soft Comput., vol. 8, no. 1, pp. 477-487, 2008.

[28] X.-S. Yang, "Bat Algorithm and Cuckoo Search: A Tutorial," in Artificial Intelligence, Evolutionary Computing and Metaheuristics: In the Footsteps of Alan Turing, X.-S. Yang, Ed. Berlin, Heidelberg: Springer Berlin Heidelberg, 2013, pp. 421-434.

[29] K.-L. Du and M. N. S. Swamy, "Ant Colony Optimization," in Search and Optimization by Metaheuristics: Techniques and Algorithms Inspired by Nature, Cham: Springer International Publishing, 2016, pp. 191-199.

[30] X. S. Y. and S. Deb, "Cuckoo Search via Lévy flights," in World Congress on Nature \& Biologically Inspired Computing (NaBIC), 2009, pp. 210-214.

[31] S. Binitha and S. Siva Sathya, "A Survey of Bio inspired Optimization Algorithms," Int. J. Soft Comput. Eng., 2012.

[32] R. Irani and R. Nasimi, "Application of artificial bee colony-based neural network in bottom hole pressure prediction in underbalanced drilling," J. Pet. Sci. Eng., 2011.

[33] S. Haykin, Neural Networks: A Comprehensive Foundation. Prentice Hall PTR, 1998.

[34] F. A. Rosenblatt, Probabilistic Model for Information Storage and Organization in the Brain. 65 Cornell Aeronautical Laboratory .

[35] Y. Shin and J. Ghosh, "The pi-sigma network: an efficient higher-order neural network for pattern classification and function approximation," in IJCNN-91-Seattle International Joint Conference on Neural Networks, 1991, vol. i, pp. 13-18 vol.1.

[36] J. W. S. Hu, Y. C. Hu, and R. R. W. Lin, "Applying neural networks to prices prediction of crude oil futures," Math. Probl. Eng., 2012.

[37] D. Sarkar, "Methods to speed up error back-propagation learning algorithm," ACM Comput. Surv., vol. 27, no. 4, pp. 519-544, 1995.

[38] H. Chiroma et al., "A Review on Artificial Intelligence Methodologies for the Forecasting of Crude Oil Price," Intell. Autom. Soft Comput., vol. 22, no. 3, p. 14, 2016.

[39] H. Naser and F. Alaali, "Can oil prices help predict US stock market returns? Evidence using a dynamic model averaging (DMA) approach," Empir. Econ., vol. 55, no. 4, pp. 1757-1777, Dec. 2018.

[40] A. Babikir and H. Mwambi, "Factor Augmented Artificial Neural Network Model,” Neural Process. Lett., vol. 45, no. 2 LB-Babikir2017, pp. 507-521, 2017.

[41] H. Shah, R. Ghazali, T. Herawan, N. Khan, and M. S. M. S. Khan, Hybrid guided artificial bee colony algorithm for earthquake time series data prediction, vol. 414. .

[42] H. Garg, M. Rani, and S. P. Sharma, "An approach for analyzing the reliability of industrial systems using soft-computing based technique," Expert Syst. Appl., 2014.

[43] J. Kennedy, R. C. Eberhart, and Y. Shi, "chapter seven - The Particle Swarm," in Swarm Intelligence, San Francisco: Morgan Kaufmann, 2001, pp. 287-325. 
[44] M. S and W. W., "Prediction Model for Crude Oil Price Using Artificial Neural Networks," Appl. Math. Sci., vol. 8, no. 80, p. 12, 2014.

[45] S. N. Abdullah and X. Zeng, "Machine learning approach for crude oil price prediction with Artificial Neural Networks-Quantitative (ANN-Q) model," in The 2010 International Joint Conference on Neural Networks (IJCNN), 2010, pp. 1-8.

[46] S. Kulkarni and I. Haidar;, "Forecasting Model for Crude Oil Price Using Artificial Neural Networks and Commodity Futures Prices," Int. J. Comput. Sci. Inf. Secur., vol. 1, no. 2, p. 8, 2009.

[47] M. Hamdi, C. Aloui, and S. kumar N. N. V.- 4, "Comparing Functional Link Artificial Neural Network And Multilayer Feedforward Neural Network Model To Forecast Crude Oil Prices," 2016.

[48] S. Gao and Y. Lei, "A new approach for crude oil price prediction based on stream learning," Geosci. Front., vol. 8, no. 1, pp. 183-187, 2017.

[49] X. Yin, J. Peng, and T. Tang, "Improving the forecasting accuracy of crude oil prices," Sustain., 2018.

[50] Y. Zhao, J. Li, and L. Yu, "A deep learning ensemble approach for crude oil price forecasting," Energy Econ., 2017.

[51] Y. Chen, K. He, and G. K. F. Tso, "Forecasting Crude Oil Prices: A Deep Learning based Model," in Procedia Computer Science, 2017.

[52] Z. Luo, X. Cai, K. Tanaka, T. Takiguchi, T. Kinkyo, and S. Hamori, "Can We Forecast Daily Oil Futures Prices? Experimental Evidence from Convolutional Neural Networks," J. Risk Financ. Manag., vol. 12, no. 1, p. 9, 2019.

[53] D. Karaboga, "2005. An Idea Based on Honey Bee Swarm for Numerical Optimization. Kayseri," Erciyes University, 2005.

[54] D. Karaboga, B. Akay, and C. Ozturk, "Artificial Bee Colony (ABC) Optimization Algorithm for Training Feed-Forward Neural Networks," in Modeling Decisions for Artificial Intelligence: 4th International Conference, MDAI 2007, Kitakyushu, Japan, August 16-18, 2007. Proceedings, V. Torra, Y. Narukawa, and Y. Yoshida, Eds. Berlin, Heidelberg: Springer Berlin Heidelberg, 2007, pp. 318-329.

[55] J. P. T. Y. Harvey Jake G. Opeña, "Automated Tomato Maturity Grading Using ABC-Trained Artificial Neural Networks," Malaysian J. Comput. Sci., vol. 30, no. 1, p. 11.

[56] D. Karaboga and B. Gorkemli, "A quick artificial bee colony (qABC) algorithm and its performance on optimization problems," Appl. Soft Comput., vol. 23, pp. 227-238, 2014.

[57] H. Shah, N. Tairan, H. Garg, R. Ghazali, and H. G. and R. G. Habib Shah, Nasser Tairan, "A Quick Gbest Guided Artificial Bee Colony algorithm for stock market prices prediction," Symmetry (Basel)., vol. 10, no. 7, p. 15, 2018.

[58] W. Gao and S. Liu, "A modified artificial bee colony algorithm," Comput. Oper. Res., 2012.

[59] G. Zhu and S. Kwong, "Gbest-guided artificial bee colony algorithm for numerical function optimization,” Appl. Math. Comput., 2010.
[60] M. Tuba, N. Bacanin, and N. Stanarevic, "Guided artificial bee colony algorithm," Proceedings of the 5th European conference on European computing conference. World Scientific and Engineering Academy and Society (WSEAS), Paris, France, pp. 398-403, 2011.

[61] N. Veček, M. Mernik, and M. Črepinšek, "A chess rating system for evolutionary algorithms: A new method for the comparison and ranking of evolutionary algorithms," Inf. Sci. (Ny)., 2014.

[62] H. Shah, N. Tairan, H. Garg, and R. Ghazali, "A Quick Gbest Guided Artificial Bee Colony Algorithm for Stock Market Prices Prediction," Symmetry (Basel)., vol. 10, no. 7, p. 292, 2018.

[63] A. Banharnsakun, T. Achalakul, and B. Sirinaovakul, "The best-so-far selection in Artificial Bee Colony algorithm," Appl. Soft Comput., vol. 11, no. 2, pp. 2888-2901, 2011.

[64] H. T. Jadhav and R. Roy, "Gbest guided artificial bee colony algorithm for environmental/economic dispatch considering wind power," Expert Syst. Appl., vol. 40, no. 16, pp. 6385-6399, 2013.

[65] N. A. Husaini, R. Ghazali, N. M. Nawi, L. H. Ismail, M. M. Deris, and T. Herawan, "PI-SIGMA NEURAL NETWORK FOR A ONE-STEPAHEAD TEMPERATURE FORECASTING," Int. J. Comput. Intell. Appl., vol. 13, no. 04, p. 1450023, Sep. 2014.

[66] T. Wu, M. Yao, and J. Yang, "Dolphin swarm algorithm," Front. Inf. Technol. Electron. Eng., vol. 17, no. 8 LB-Wu2016, pp. 717-729, 2016.

[67] H. Shah, R. Ghazali, N. M. Nawi, and M. M. Deris, Global hybrid ant bee colony algorithm for training artificial neural networks, vol. 7333 LNCS, no. PART 1. 2012.

[68] E. Hancer and D. Karaboga, "A comprehensive survey of traditional, merge-split and evolutionary approaches proposed for determination of cluster number," Swarm Evol. Comput., vol. 32, pp. 49-67, 2017.

[69] H.-B. Duan, C.-F. Xu, and Z.-H. Xing, "A hybrid artificial bee colony optimization and quantum evolutionary algorithm for continuous optimization problems.," Int. J. Neural Syst., vol. 20, no. 1, pp. 39-50, 2010.

[70] X. S. Yang and Suash Deb, "Cuckoo Search via Lévy flights," in World Congress on Nature \& Biologically Inspired Computing (NaBIC), 2009, pp. 210-214.

[71] D. Karaboga and C. Ozturk, "A novel clustering approach: Artificial Bee Colony (ABC) algorithm," Appl. Soft Comput., vol. 11, no. 1, pp. 652-657, 2011.

[72] D. Karaboga and B. Akay, "A survey: Algorithms simulating bee swarm intelligence," Artif. Intell. Rev., 2009.

[73] Kabbani and B. F., "Gulf Base," Price Performance Charts, 2017. [Online]. Available: http://www.gulfbase.com/. 